University of Redlands

\title{
A Geographic Database Design for Humanitarian Assistance and Disaster Response
}

A Major Individual Project submitted in partial satisfaction of the requirements for the degree of Master of Science in Geographic Information Systems

By

Douglas E. Weinstein

Committee in charge:

Mark Kumler, Ph.D., Chair

Karen Kemp, Ph.D.

Ray Carnes

Shawn Messick

Eric Sawyer 
A Geographic Database Design for Humanitarian Assistance and Disaster Response

Copyright (C) July 2005

by

Douglas E. Weinstein 
The report of Douglas E. Weinstein is approved.
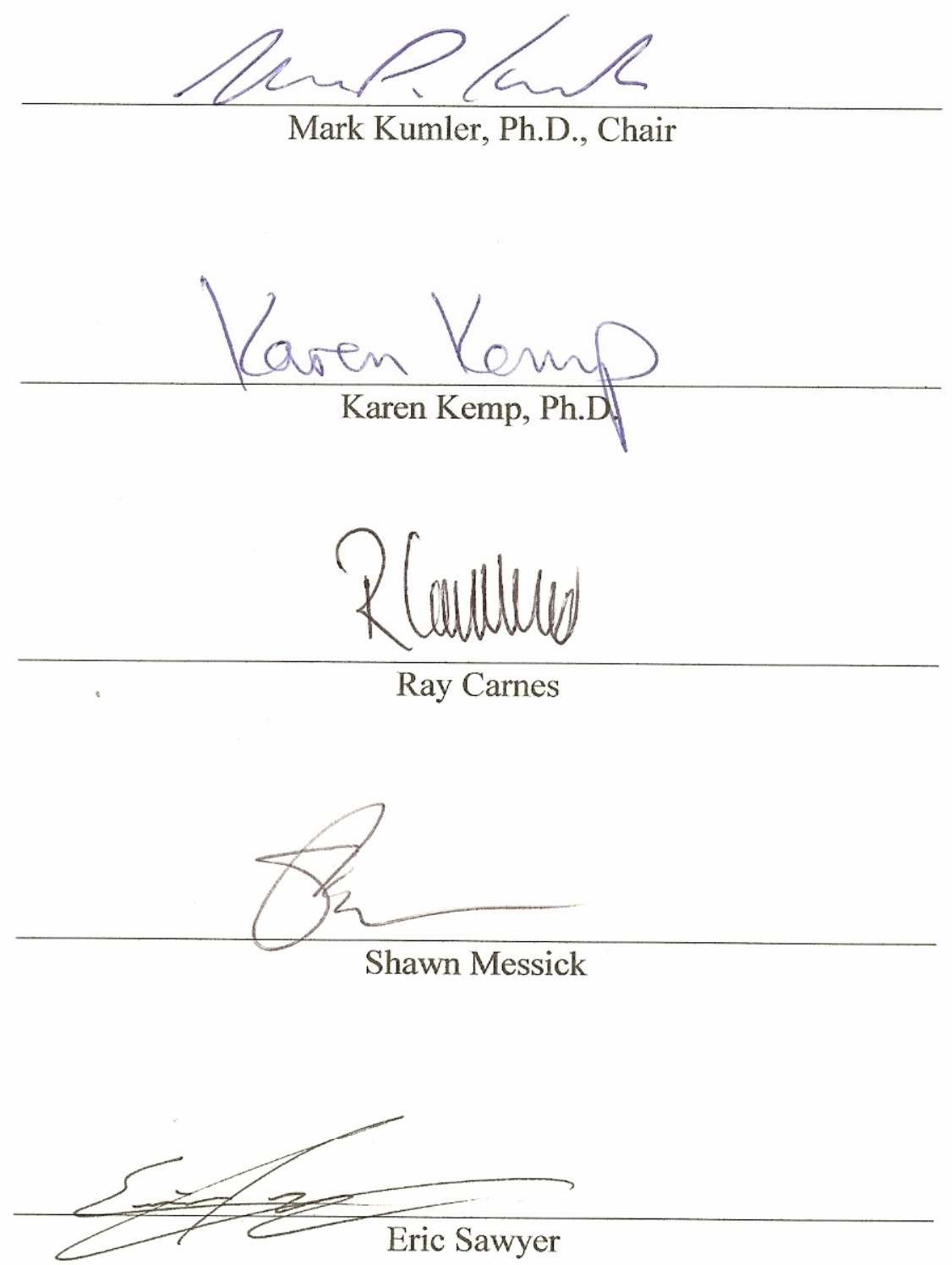

July 2005 



\section{ACKNOWLEDGEMENTS}

First and foremost, I would like to thank my family and those closest to me for their continued support and patience during this year while I completed the MSGIS Program at the University of Redlands. Secondly, this accomplishment would not be possible without the educational assistance from the National Geospatial-Intelligence Agency (NGA). Thirdly, I would like to acknowledge Karen Kemp, Mark Kumler, Theresa Ellis, and all the staff at the University of Redlands who work with the MSGIS Program for sharing their knowledge, resources, and guidance. And lastly, I would like to thank Ray Carnes, Shawn Messick, and Eric Sawyer for serving as members of my Committee and all the other professionals mentioned in this Project for their significant support. 


\begin{abstract}
A Geographic Database Design for Humanitarian Assistance and Disaster Response

By

Douglas E. Weinstein
\end{abstract}

The international humanitarian assistance community responds to a wide variety of crises and disasters that are challenging in their variability, scale, timelines, resources, and politics. The implementation of a geographic database model, or Geodatabase, of geographic information resources will provide emergency responders with a functional relational database to support disaster response missions. The Geodatabase will be compact and deployable, improve functionality and efficiency, reduce error, increase standardization, and record an institutional knowledge base. Distributing the Geodatabase model in the form of a WebGIS website can additionally facilitate organizational communication and decision-making during the phases of emergency management by providing a thematic attribute query search capability.

This Project will serve as a proof-of-concept design for future potential implementation and enhancement of the recommended models. The December 26, 2004 tsunami disaster in Indonesia and the surrounding region is the primary study area for this project. The recommendations outlined in this Project will help to support the initial data delivery steps of future humanitarian assistance and disaster response missions.

Keywords: Geodatabase, WebGIS, USAID, OFDA, Humanitarian Assistance, Disaster Response, Emergency Management, Tsunami 


\section{TABLE OF CONTENTS}





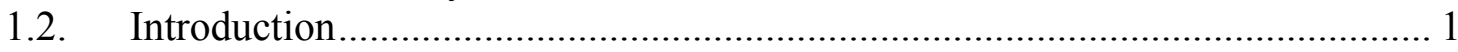

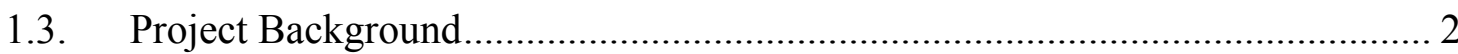

1.4. Emergency Management Phases.................................................................. 2

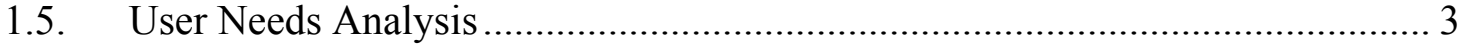

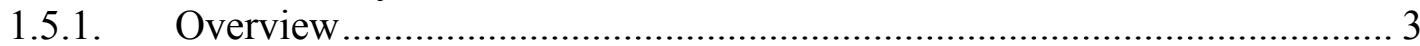

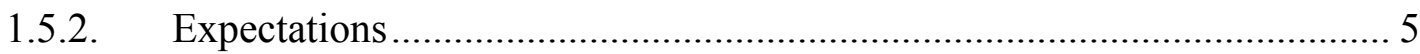

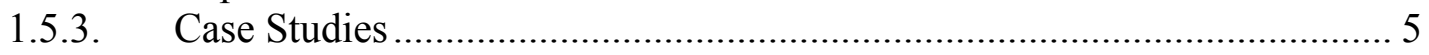

1.5.4. Information Management and Data Sources.............................................. 5

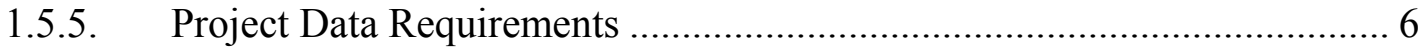

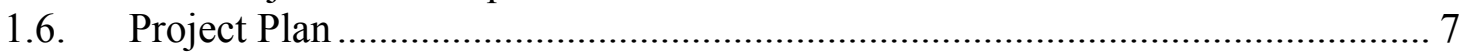



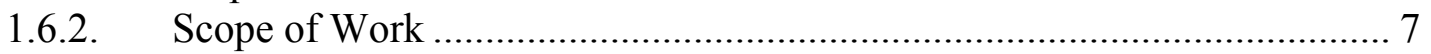



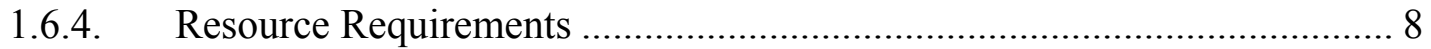



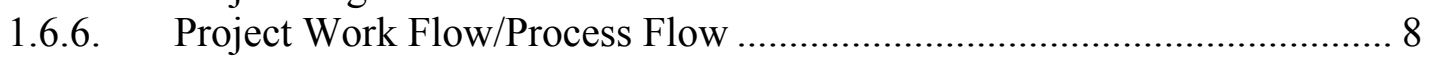

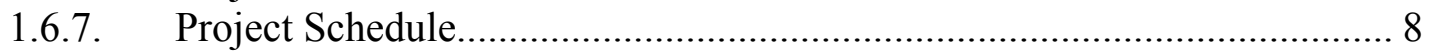

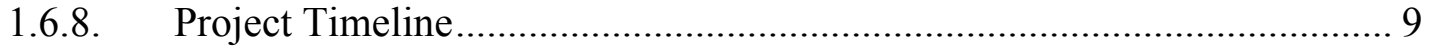

1.6.9. Monitoring, Communicating, and Reporting ........................................... 9

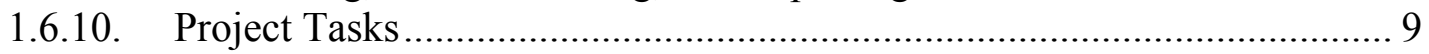





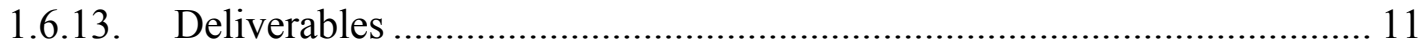



2.1. Geographic Data Collection and Review..................................................... 13

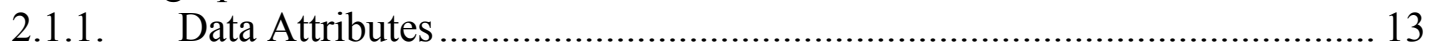

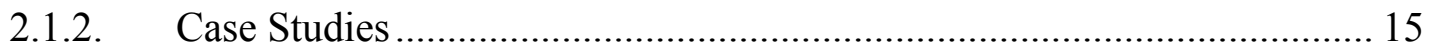

2.2. Geographic Database Design ................................................................ 15



2.2.2. Geodatabase Terms ....................................................................... 15

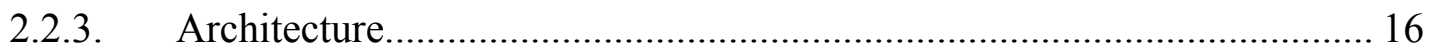

2.2.4. RDBMS Storage ........................................................................... 16

2.2.5. ESRI Geodatabase Overview............................................................ 17

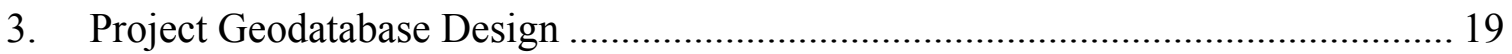

3.1. Solution Proposal Overview ..................................................................... 19





3.3.1. Conceptual Model Overview ............................................................... 21



3.3.3. Conceptual Model Design...................................................................... 21 


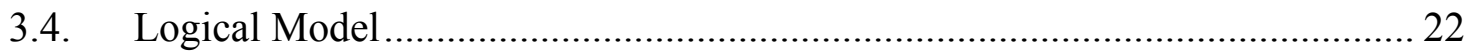

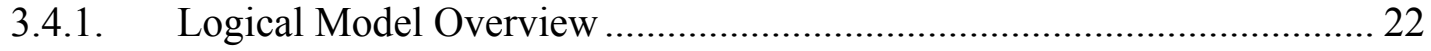

3.4.2. Logical Model Terms................................................................... 22

3.4.3. Logical Model Design................................................................... 23

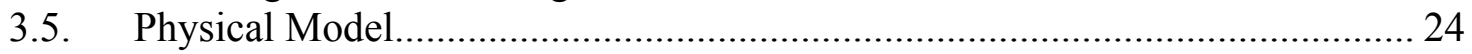

3.5.1. Physical Model Overview................................................................. 24

3.5.2. Physical Model Terms ........................................................................ 24

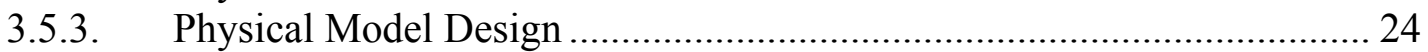

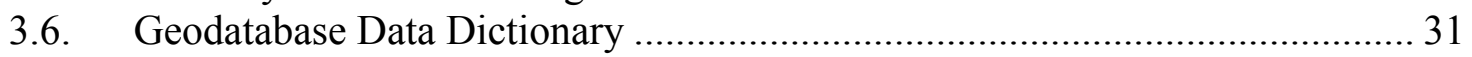

3.6.1. Data Dictionary Thematic Layers .......................................................... 32



3.7. Geodatabase Design Implementation Stages ………………………….......... 37

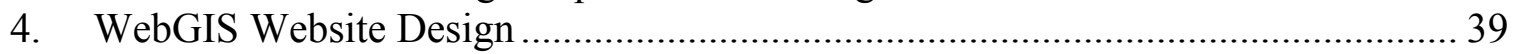

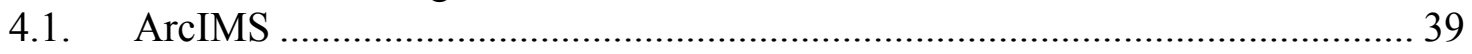

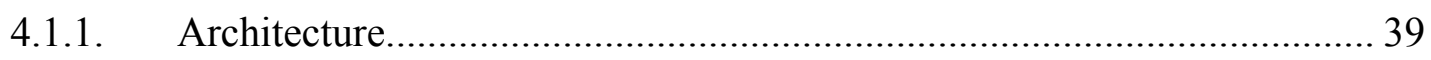

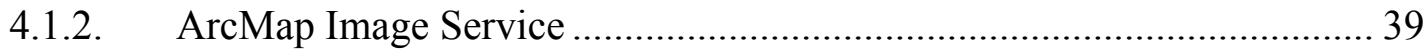

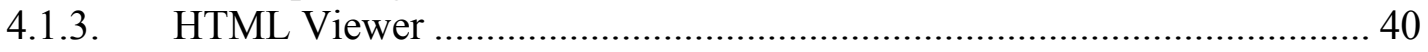

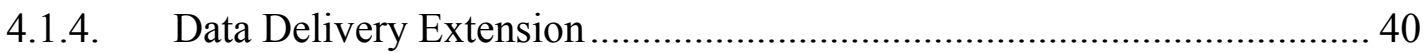

4.1.5. Thematic Attribute Query …………………............................................. 40

4.1.6. WebGIS Website Viewer Design ............................................................. 41



5.1. Quality Assurance/Quality Control (QA/QC) Plan ........................................... 43

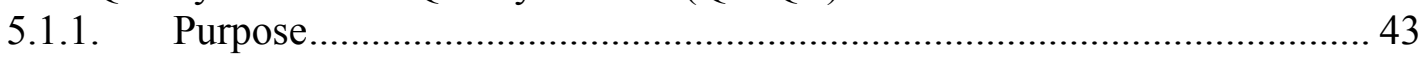

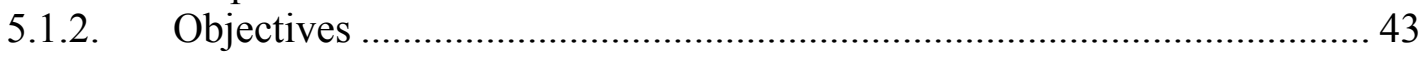

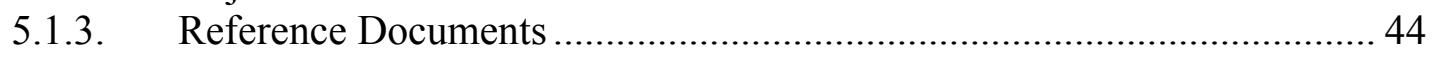

5.1.4. Acceptance Criteria Specifications ………………................................... 44

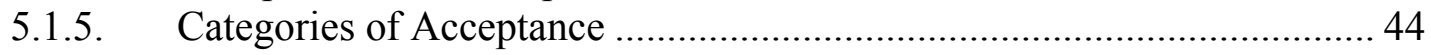

5.1.6. Visual Quality Control Checks .................................................................. 44



5.1.8. Quality Control Documentation............................................................... 44

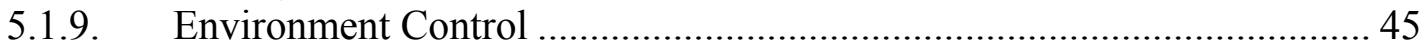

5.1.10. Quality Monitoring, Analysis, and Improvement .................................... 45

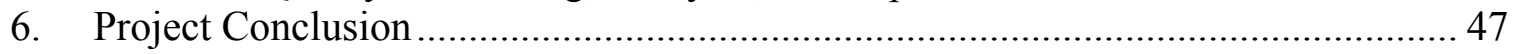

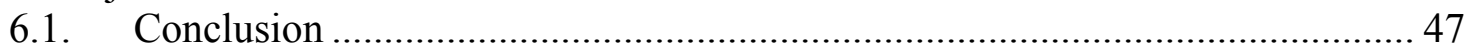

6.2. Geodatabase Development Support............................................................ 47

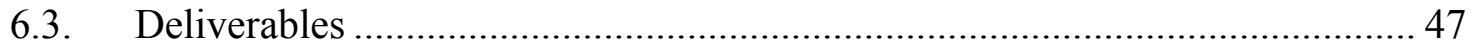

6.3.1. Project Documentation.............................................................................. 48

6.3.2. Geodatabase and WebGIS Website ........................................................ 48

6.4. Humanitarian Community Support........................................................... 48



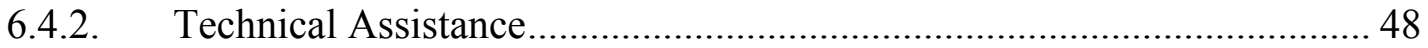

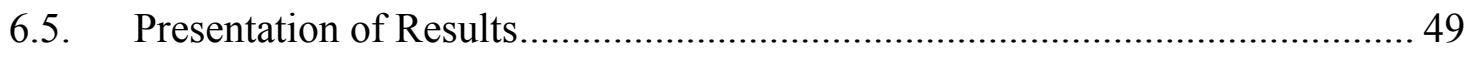

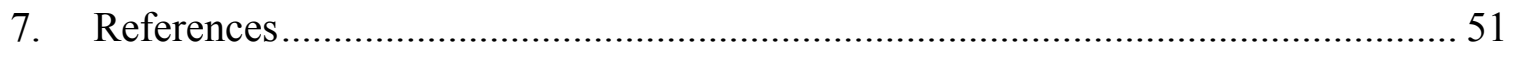

Appendix A: USAID/OFDA Data Inventory Examples................................................. 55

Appendix B: Project Data Requirements .................................................................... 57

Appendix C: Project Work Flow/Process Flow............................................................ 58 


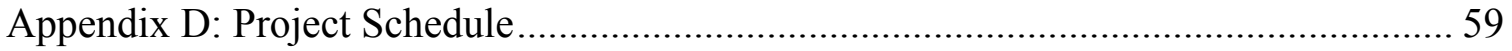

Appendix E: Project Tasks........................................................................................ 60

Appendix F: Quality Assurance/Quality Control Work Flow ......................................... 61

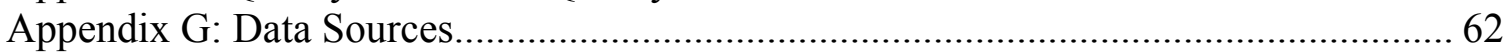

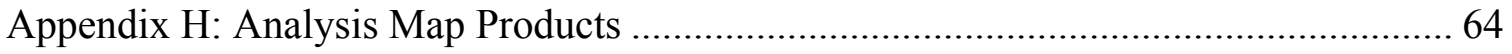




\section{LIST OF FIGURES}

Figure 1: USAID/OFDA Organization [USAID, 2003, p. 14] …............................... 4

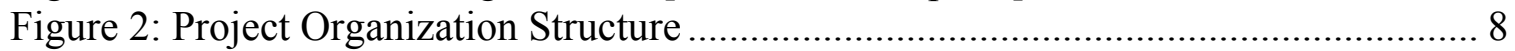



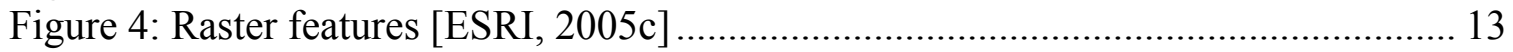

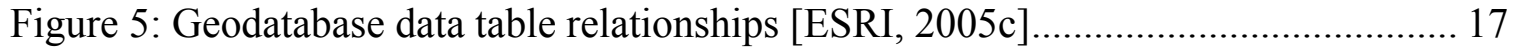

Figure 6: ESRI Geodatabase and ArcGIS Products [ESRI, 2005c] ............................... 17

Figure 7: Geodatabase Design Process [Arctur and Zeiler, 2004, p. 9] ........................... 20

Figure 8: Geodatabase schema example in ESRI ArcCatalog ..................................... 25

Figure 9: Example of an Airport Subtype Schema .................................................. 28

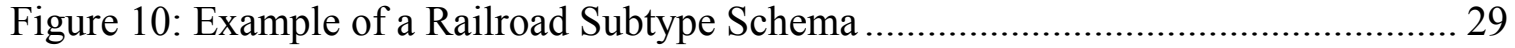

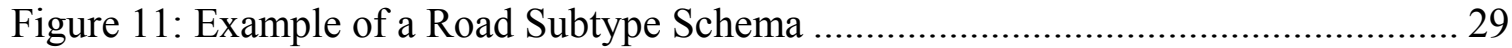

Figure 12: Example of a Utility Line Subtype Schema ............................................ 30

Figure 13: Example of an Earthquake Intensity Zone Subtype Schema ......................... 30



Figure 15: Data Dictionary and Selected Geodatabase System Tables .......................... 33

Figure 16: Data dictionary table using EMER_TYPE coded value domain ................... 35

Figure 17: Geodatabase Implementation Process [Arctur and Zeiler, 2004, p. 377]........ 37



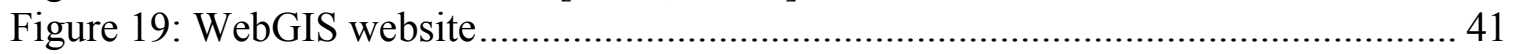

Figure 20: WebGIS website with Base Layer data selection........................................ 41

Figure 21: WebGIS website with Tsunami data selection............................................ 42

Figure 22: WebGIS website with Earthquake data selection........................................ 42

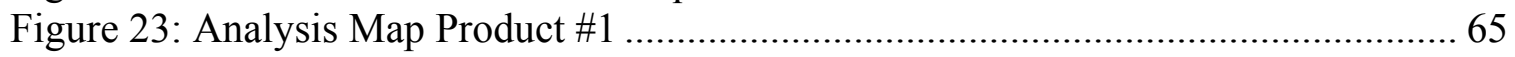

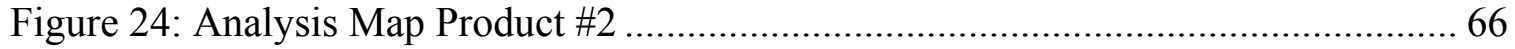




\section{LIST OF TABLES}

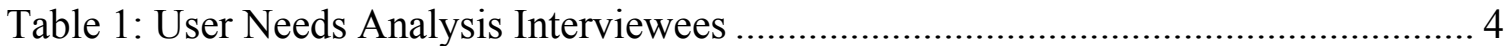

Table 2: Logical Model Feature Classes.......................................................................... 23

Table 3: Logical Model Raster Datasets ....................................................................... 24

Table 4: Example of a Data Source Coded Value Domain Schema............................... 26

Table 5: Example of an Emergency Type Coded Value Domain Schema ....................... 27

Table 6: Example of an Earthquake Magnitude Coded Value Domain Schema.............. 27

Table 7: FEMA HazardMaps.gov Thematic Layers [FEMA, 2005] ................................ 32






\section{LIST OF ACRONYMS}

CRED Centre for Research on the Epidemiology of Disasters

DART Disaster Assistance Response Team

DEM Digital Elevation Model

DFID United Kingdom Department for International Development

DFO Dartmouth Flood Observatory

ESRI Environmental Systems Research Institute

FAO Food and Agriculture Organization of the United Nations

FEMA Federal Emergency Management Agency

GDB Geodatabase

GIS Geographic Information System

GIST Geographic Information Support Team

HIC Humanitarian Information Center

HIU Humanitarian Information Unit

HTML Hypertext Markup Language

ICRC International Committee of the Red Cross/Red Crescent

iMMAP Information Management and Mine Action Program

IMS Internet Map Server

IO International Organization

MIS Management Information System

NGA National Geospatial-Intelligence Agency

NGDC National Geophysical Data Center

NGO Non-Governmental Organization

NOAA National Oceanic and Atmospheric Administration

OCHA United Nations Office for the Coordination of Humanitarian Affairs

OFDA United States Office of Foreign Disaster Assistance

PDC Pacific Disaster Center

QA/QC Quality Assurance/Quality Control

RDBMS Relational Database Management System

UML Unified Modeling Language

UN United Nations

UNDP United Nations Development Programme

UNEP United Nations Environment Programme

USAID United States Agency for International Development

USG United States Government

USGS United States Geological Survey

VVAF Vietnam Veterans of America Foundation

WFP World Food Programme

WHO World Health Organization 


\begin{abstract}
AUTHOR'S NOTE
The recommendations and opinions expressed throughout this Project are those of the Author only and do not necessarily represent the views of the United States Government, the National Geospatial-Intelligence Agency, the United States Agency for International Development, the University of Redlands, ESRI, or any other person and/or organization referenced herein. These conclusions are based upon the Author's interpretation of the current and future needs of the international humanitarian community based upon information collected during the course of this Project.
\end{abstract}




\section{Project Definition}

\subsection{Executive Summary}

Relational databases of geographic information, such as a geodatabase or an enterprise GIS, can provide enhanced effectiveness and efficiency in support of emergency management and disaster response operations. The delivery of geographic information in a geodatabase enhances data discovery through the use of an advanced organization methodology and thematic attribute query capability. This Geodatabase serves as a basic proof-of-concept model and the future development of an enterprise GIS will provide a more robust and versatile framework for the international humanitarian community to build upon.

\subsection{Introduction}

The international humanitarian community responds to a wide variety of crises and disasters that are challenging in their variability, scale, timelines, resources, and politics. Significant challenges exist concerning the implementation of a standard geographic database framework of information resources that can be delivered to a humanitarian relief effort quickly. It has been recognized that "the humanitarian community is not harnessing the full potential of modern information management capacity" [Sida and Szpak, 2004, p. 4] and that major requirements such as the "timeliness and updating of information and standardization" [Meissner et al., 2002, p. 2] have not been met. A geographic database model, or Geodatabase, has been developed for the intended implementation by international organizations (IOs) within the humanitarian community for emergency management and disaster response operations. The Geodatabase can be delivered by the host organization directly and/or indirectly through a WebGIS website that is accessible to the humanitarian community to support field activities. The WebGIS website is viewable using any HTML internet browser and provides data analysis and export functionality to emergency responders.

Currently, organizations such as the United Nations, United States Geological Survey, Federal Emergency Management Agency, Humanitarian Information Unit, ESRI, Pacific Disaster Center, Vietnam Veterans of America Foundation Information Management and Mine Action Program, Mercy Corps, and other NGOs currently provide large repositories of data that are accessible to the humanitarian community and public. The metadata servers, WebGIS websites, and FTP sites that serve the data are very rarely designed to support thematic attribute queries, to be disaster focused, indexed, or field application ready. A significant investment in time and resources is usually required to identify the available and applicable geographic information required for a response. A WebGIS website with an enhanced thematic query capability improves data discovery and makes analysis and production more efficient and effective.

Humanitarian assistance organizations such as the U.S. Agency for International Development Office of U.S. Foreign Disaster Assistance (USAID/OFDA) can potentially implement this model within its current emergency response activities. The focus of this 
project is to design a Geodatabase model that utilizes an internet-based delivery mechanism to support the thematic query of geographic information.

\subsection{Project Background}

“On 26 December 2004, an extremely strong earthquake (8.9 on the Richter scale) occurred below the Indian Ocean, northwest of Sumatra Island. This earthquake, that later caused a tsunami wave, ravaged the most part of Aceh and Nias in Indonesia, a part of Thailand, Sri Lanka, Maldives, Bangladesh, Myanmar, even Somalia's coast in East Africa. In Aceh and Nias, the earthquake and tsunami wave damaged the most part of Aceh's coastal areas, claiming heavy casualties, destroyed infrastructure, settlements, social facilities such as schools, health centers, security, social and public economic, and government buildings" [Republic of Indonesia, 2005, p. I-1].

This disaster also affected the social and economic condition of the people, including their psychological condition and welfare level. According to the Centre for Research on the Epidemiology of Disasters (CRED), the tsunami accounted for "nearly 94\% of all recorded deaths from natural disasters for [2004]" [CRED, 2005].

The humanitarian assistance response to the Indonesia tsunami disaster serves as the primary case study and application for this project. The recommendations made within focus on improving geographic information storage and delivery in support of disaster response and recovery activities. The need for improved geographic information storage models and data sharing mechanisms is supported by one of the stated objectives of the Republic of Indonesia Master Plan to "disseminate and distribute data as well as information to local, national and international communities with respect to the disaster, disaster aftermath, damage and loss assessment, need assessment, as well as early warning system in anticipation of any exposure to disaster" [Republic of Indonesia, 2005, p. I-2]. Additionally, the report identifies three main geographic information issues that would expedite future humanitarian assistance activities: "1) the availability of accurate, comprehensive and up to date data/information; 2) easy access to such data/information; and 3) the uniformity of data/information delivered" [Republic of Indonesia, 2005, p. 93]. The model designs for the Geodatabase and WebGIS website support these issues.

\subsection{Emergency Management Phases}

The concept of emergency management can be described as the "guiding, coordinating, and application of all the sources of all organizations and associations for the common purpose of preventing loss and decreasing disaster damage" [Eraslan et al., 2004, p. 1]. Traditionally, emergency management activities are organized into four phases "that are related by time and function to all types of emergencies and disasters" [Johnson, 2000, p. 2]. These phases, recognized by virtually all emergency management organizations, help to facilitate planning and categorize roles and responsibilities in a crisis. "GIS is widely used [in the emergency management phases] to create more effective and efficient disaster management" [Mansourian et al., 2004, p. 2]. Most humanitarian assistance 
activities occur within the Response and Recovery emergency management phases as a result of the unplanned nature of natural disasters. For context and reference, the emergency management phases are described below: [FEMA, 2002, p. iii]

- Mitigation: Taking sustained actions to reduce or eliminate long-term risk to people and property from hazards and their effects.

- Preparedness: Building the emergency management profession to prepare effectively for, mitigate against, respond to, and recover from any hazard by planning, training, and exercising.

- Response: Conducting emergency operations to save lives and property by positioning emergency equipment and supplies; evacuating potential victims; providing food, water, shelter, and medical care to those in need; and restoring critical public services.

- Recovery: Rebuilding communities so individuals, businesses, and governments can function on their own, return to normal life, and protect against future hazards.

\subsection{User Needs Analysis}

\subsubsection{Overview}

USAID/OFDA's mission is to save lives, alleviate human suffering, and reduce the economic and social impacts of disasters. Additionally, OFDA plans for, provides and coordinates assistance to those affected by natural and man-made international crises and disasters. This humanitarian assistance is provided in response to a declaration of an international crisis or disaster made by the U.S. Chief of Mission, the U.S. Ambassador, or the U.S. Department of State. A Disaster Declaration Cable is written if: 1) the host country's government requests or is willing to receive international assistance, 2) the disaster exceeds the ability of the host country to respond, and 3) the response is in the best interest of the U.S. Government (USG).

Once the Disaster Declaration Cable is sent to USAID/OFDA, one or more of the following actions may occur: [USAID Pamphlet, 2004]

- Provision of funds to the U.S. Embassy if USAID Mission.

- Deployment of one or more USAID/OFDA regional advisors to the disaster site to assess conditions and identify needs.

- Deployment of an USAID/OFDA assessment team to evaluate the disaster situation.

- Deployment of a Disaster Assistance Response Team (DART) to the affected country or region to coordinate USG disaster response. 
- Funding of grant proposals submitted to USAID/OFDA by International Organizations (IOs) and Non-Governmental Organizations (NGOs).

- Provision of disaster relief commodities from USAID/OFDA's stockpiles.

- Deployment of technical and sectoral experts.

Any of these disaster response and recovery activities usually last between 30 and 90 days after activation. The USAID/OFDA Geographic Information Unit (GIU), which is a regional team in the Disaster Response and Mitigation Division (DRM) of USAID's Bureau for Democracy, Conflict, and Humanitarian Assistance (DCHA), would be the entity most directly involved with the project's recommendations (see Figure 1). Most geographic data and map product delivery would be coordinated between the GIU and deployed USAID/OFDA resources, such as a DART.

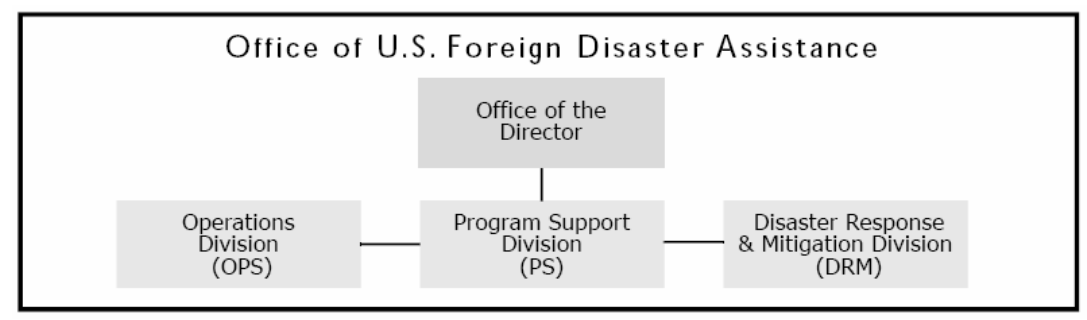

Figure 1: USAID/OFDA Organization [USAID, 2003, p. 14]

The User Needs Analysis has been developed from multiple phone conversations, emails, interviews, meetings, and conferences with members of the USAID/OFDA Geographic Information Unit (GIU), Geographic Information Support Team (GIST), National Geospatial-Intelligence Agency (NGA), and other professionals and academics. The interviewees are listed in Table 1.

Table 1: User Needs Analysis Interviewees

\begin{tabular}{|l|l|l|}
\hline Tim Foresman & $\begin{array}{l}\text { International Center for Remote } \\
\text { Sensing of Environment (ICRSE) }\end{array}$ & ICRSE Director \\
\hline Nate Smith & USAID/OFDA & $\begin{array}{l}\text { Technical Coordinator/Geographic } \\
\text { Information Specialist }\end{array}$ \\
\hline Dong Chung & USAID/OFDA & Cartographer \\
\hline Bob Walker & Macfadden & OFDA Training Coordinator \\
\hline Eric Sawyer & $\begin{array}{l}\text { Geographic Information Support Team } \\
\text { (GIST) }\end{array}$ & Data Repository Manager \\
\hline Neal Stewart & $\begin{array}{l}\text { National Geospatial-Intelligence } \\
\text { Agency (NGA) }\end{array}$ & $\begin{array}{l}\text { NGA Environmental Security } \\
\text { Branch Chief }\end{array}$ \\
\hline Shawn Messick & $\begin{array}{l}\text { Vietnam Veteran's of America } \\
\text { Foundation (VVAF) }\end{array}$ & $\begin{array}{l}\text { Technical Director of VVAF } \\
\text { Information Management and Mine } \\
\text { Action Program }\end{array}$ \\
\hline Michael Goodchild & $\begin{array}{l}\text { University of California at Santa } \\
\text { Barbara (UCSB)/NCGIA }\end{array}$ & $\begin{array}{l}\text { NCGIA Chair of the Executive } \\
\text { Committee }\end{array}$ \\
\hline
\end{tabular}




\subsubsection{Expectations}

Correspondence and meetings with USAID/OFDA have allowed for a very open dialogue about how to better understand the complexity of humanitarian assistance and disaster response challenges. These problems require a thorough understanding of the social, political, ethnic and cultural problems that challenge a viable solution as much as the respective geographic information aspects. A geographic database model has been developed as an adaptable standard dataset of geographic information in both raster and vector format to help address some of these issues. While it is impossible to anticipate all future geographic information requirements and standards in regard to emergency management, the development and dissemination of a Geodatabase via a WebGIS website provides an end-user with a better standard data framework and inherent analytic capabilities for rapid response.

\subsubsection{Case Studies}

USAID/OFDA has provided materials and geographic information from several recent international disaster response and recovery efforts in addition to the widely available public information regarding the December 26, 2004 Indonesia tsunami. The evaluation of the data collected for these case studies, which include the January 17, 2002 Democratic Republic of Congo (DRoC) Nyiragongo volcanic eruption, the December 26, 2003 Bam, Iran earthquake, and the 2003-2004 Sahelian Africa locust emergency (see Appendix A), have revealed what is critical for humanitarian assistance rapid response support and where data gaps have existed in. This information has been used to construct a list of data requirements for many humanitarian assistance and disaster response activities.

\subsubsection{Information Management and Data Sources}

During the initial response time, it is critical that OFDA provides the Disaster Assistance Response Team (DART) and other humanitarian assistance organizations with the necessary geographic information to support the emergency response needs in the field. While the United Nations, in some cases, provides the overall coordination of information dissemination and establishes a Humanitarian Information Center (HIC), the GIU is responsible for coordinating OFDA's data delivery to its support activities. The Technical Coordinator/Geographic Information Specialist may prepare and deliver available data and/or logistics support directly to the field. In most cases, the data repository of the Geographic Information Support Team (GIST) more broadly disseminates data to the humanitarian community.

As the DART receives information from Non-Government Organizations (NGOs) in the host country, this information is shared with the Cartographer who combines it with the existing geographic information to create a deliverable product for decision-makers and the humanitarian community. The unpredictable type and rapid response nature of an emergency makes it very challenging to provide data delivery standards and value-added analysis when responding to ad hoc requirements. 


\subsubsection{Geographic Information Support Team (GIST)}

The Geographic Information Support Team (GIST) is "an inter-agency initiative that promotes the use of geographic data standards and geographical information systems (GIS) in support of humanitarian relief operations" [Geographic Information Support Team, Data Repository, 2005]. Originally formed as a United Nations (UN) pilot project in 1998 to organize and share information within the humanitarian community, the GIST has supported crises in Kosovo, Afghanistan, Goma, the Democratic Republic of Congo (DRoC), southern Africa, Iraq, and Indonesia. "GIST members are technical experts, geographic information specialists and information management officers from UN and donor agencies involved in disaster management and/or humanitarian assistance. The United Nations Office for the Coordination of Humanitarian Affairs (OCHA) acts as the GIST secretariat" [Geographic Information Support Team, Data Repository, 2005]. To support of its global data management and integration needs, the GIST set up a Data Repository in collaboration with the Information Technology Outreach Services (ITOS) of the University of Georgia. The GIST is currently funded by USAID/OFDA.

\subsubsection{Humanitarian Information Centre}

A Humanitarian Information Centre (HIC) supports "the co-ordination of humanitarian assistance through the provision of information products and services and the decisionmaking process at headquarters and field level by contributing to the creation of a common framework for information management within the humanitarian community" [OCHA, 2005]. As a focal point for data collection, analysis, and dissemination, the activated HIC will utilize the resources of the DART and GIST, as well as local institutions and NGOs, to collect as much relevant geographic information as possible. The HICs are intended as a "single stop shop for all aspects of information management and exchange (meetings, mail, database management, mapping) and are focused on providing comprehensive data to operational partners" [Geographic Information Support Team, Data Repository, 2005].

\subsubsection{Project Data Requirements}

USAID/OFDA has identified a selection of base layers that would ideally make up the initial geographic information framework to build upon. For most emergencies and disasters, these data requirements would include thematic information such as populated places, administrative boundaries, buildings, transportation infrastructure, natural features, terrain, and satellite and aerial imagery. Some unique disasters, such as earthquakes and floods, may require additional geophysical and hydrographic data such as faults and historic quakes, slopes, water bodies, and land use/land cover. Additionally, information about "available resources, access to roads and damaged areas, required resources, and required disaster response operations that should be available and accessible" [Mansourian et al., 2004, p. 1] has also been identified as necessary to successfully respond to an emergency. These data requirements are presented in greater detail according to specific data layers in Appendix B. 


\subsection{Project Plan}

\subsubsection{Purpose}

This Project Plan serves to document all the basic information and plans for implementing the project $A$ Geographic Database Design for Humanitarian Assistance and Disaster Response. It defines the technical and managerial processes required to satisfy the requirements of the project and to meet the terms and conditions of the project. The Project Manager of the Geodatabase and WebGIS website implements the following Project Plan elements.

\subsubsection{Scope of Work}

- The Project Manager will identify the current geographic information needs of organizations within the humanitarian community.

- The Project Manager will review past emergency response events that USAID/OFDA has supported and design a geographic information framework of critical layers.

- The Project Manager will develop a Geodatabase model to increase organization and facilitate the emergency response capabilities of humanitarian relief organizations within the humanitarian community.

- The Project Manager will develop a WebGIS Website to disseminate geographic information though an internet browser to the humanitarian community.

\subsubsection{Assumptions}

- Representatives from participating humanitarian aid organizations will respond in a timely manner to all related correspondence and participate in scheduled meetings. Non-timely responses and lack of participation will delay the project schedule.

- Representatives from coordinating humanitarian assistance organizations will provide necessary data and documentation from both past and current emergency response activities. Incomplete data collection and background information could negatively impact project development and final recommendations.

- Users of the Geodatabase and WebGIS will have the minimum required technology capability to support this research (e.g. ArcGIS or ArcReader and ArcIMS or a web browser). Insufficient technology resources will inhibit the users' abilities to use the Geodatabase and WebGIS and associated data.

- The Geodatabase and WebGIS website designs will provide the user a solution for how these technologies can be used for geographic information storage and distribution and illustrates only one methodology. 


\subsubsection{Resource Requirements}

The project will be completed using ESRI's ArcGIS and ArcIMS software. ArcGIS 9.1 will be used to process the geographic data and create the corresponding personal Geodatabase. ArcIMS 9.1 will be used to create the WebGIS website that will share the geographic data through a web browser connected to the internet. While these software licenses are recommended for optimal functionality and customization, the humanitarian community can use any software that supports vector and raster data formats (e.g. MapInfo, GeoMedia, Idrisi, etc.) and any web browser connected to the internet to view the WebGIS website. Additionally, ESRI provides the ArcReader mapping application free to the public at http://www.esri.com/software/arcgis/arcreader/index.html).

\subsubsection{Project Organization Structure}

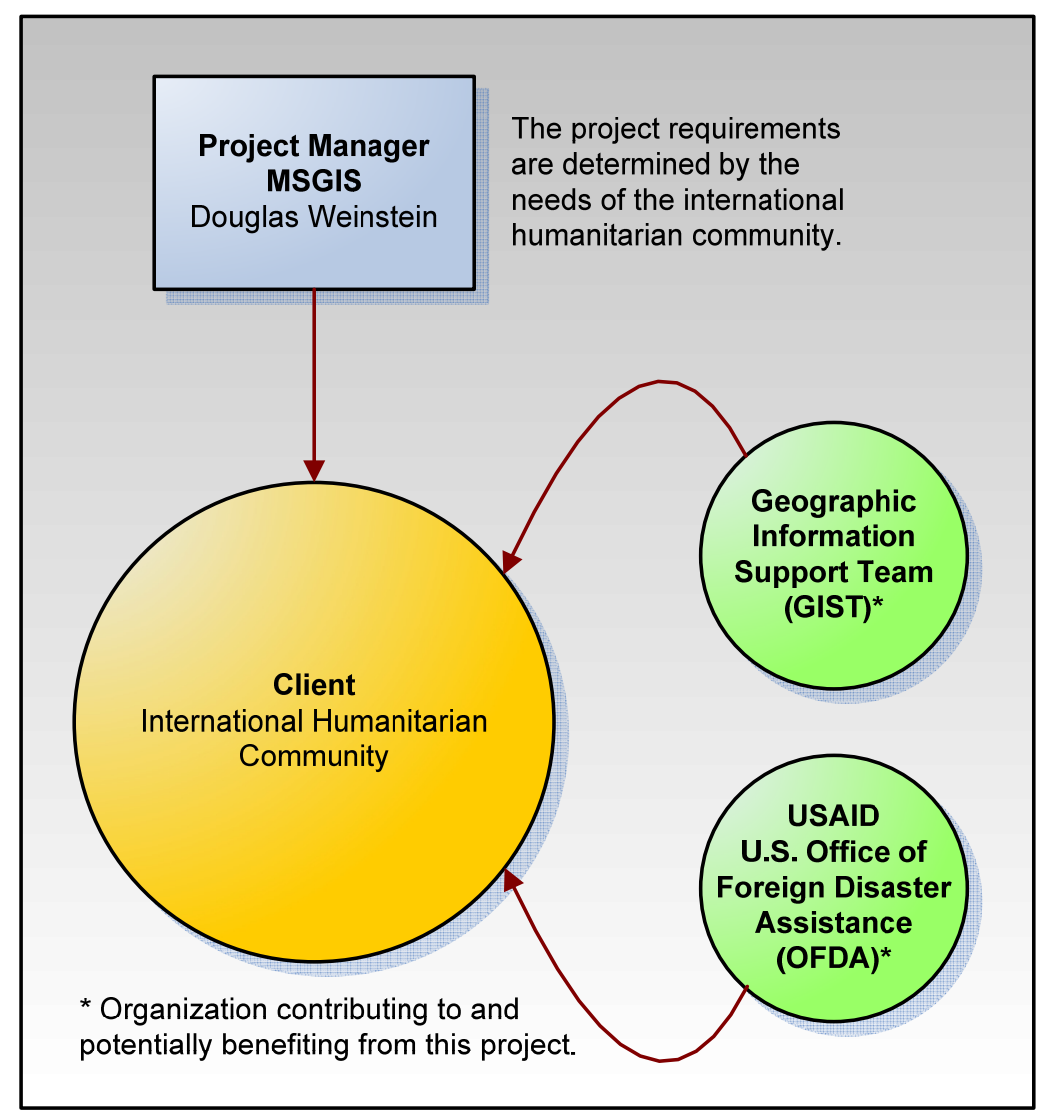

Figure 2: Project Organization Structure

\subsubsection{Project Work Flow/Process Flow}

See Appendix C.

\subsubsection{Project Schedule}

See Appendix D. 


\subsubsection{Project Timeline}

See Appendix E.

\subsubsection{Monitoring, Communicating, and Reporting}

The communication plan for the Geographic Database Design project includes the following topics related to communication: audience, reason, format, responsibility, medium, frequency, and content. The audience of most communication includes individuals and organizations that are both contributing and benefiting from this project. This includes OFDA, the National Geospatial-Intelligence Agency (NGA), and the Geographic Information Support Team (GIST). Communication with these stakeholders is important to continue support of the project in the form of geographic information sharing. These communications have been relatively informal in the form of emails, conference calls, and shared data. Occasionally more formal meetings have been required with stakeholders to discuss and/or present project issues. The project manager has been responsible for initiating most communications with the humanitarian community and clients on a regular monthly schedule or as-needed basis. The content of most communications has focused on the development of the project and future applications of the research.

\subsubsection{Project Tasks}

\section{Task 1: Humanitarian Community Needs Analysis}

The Project Manager will schedule multiple phone conversations, emails, interviews, and meetings with organizations within the humanitarian community. These correspondences and meetings will allow the Project Manager to more accurately determine the operational needs of the Geodatabase model. As mentioned in the User Needs Analysis overview, interviewees include members of the USAID/OFDA Geographic Information Unit (GIU), Geographic Information Support Team (GIST), National GeospatialIntelligence Agency (NGA), and other professionals and academics (see Table 1).

\section{Task 2: Data Inventory and Business Practice Review}

The Project Manager will conduct a data inventory of the geographic information that has been previously utilized by a DART in the event of an international emergency. With guidance from OFDA, the Project Manager will also determine a selection of base layers that would make up the framework of the Geodatabase based upon current and future requirements and needs. Reviewing historical case studies and understanding how a humanitarian assistance organization traditionally conducts business will help to more accurately develop the Geodatabase model.

\section{Task 3: Geodatabase and WebGIS Website Research}

The Project Manager will research and identify technology solutions that can be easily implemented within the current operating environment of the humanitarian community. The research will focus on geographic database design and WebGIS website design. 


\section{Task 4: Project Plan and Quality Assurance Plan}

The Project Manager will serve as both the Project Plan Team and Quality Assurance Team. This responsibility includes developing and implementing the Project Plan (see Section 1.5) and Quality Assurance Plan (see Section 5.1).

\section{Task 5: Conceptual and Logical Geodatabase Design}

The Project Manager will develop the initial conceptual design of the Geodatabase based upon the information gained from the Client's user needs analysis, data inventory, and business practice review. The Geodatabase conceptual design will be based upon the thematic geographic data that are determined from discussions with OFDA. The scale of the data will be no smaller than 1:250,000. The Geodatabase logical design will consist of feature classes organized into feature datasets with coded-value domains. Coded-value domains will be used to identify the data type, data provider, data user, application category, derived dataset, and emergency classification type for the each layer.

\section{Task 6: Physical Geodatabase Design}

The Project Manager will develop the physical Geodatabase based upon the reviewed conceptual and logical design parameters.

\section{Task 7: WebGIS Website Development}

The Project Manager will develop an HTML-based WebGIS website using ESRI ArcIMS software. This ArcIMS website can be viewed by any internet browser and the available data can be used within the website for web-based analysis purposes or exported for local analysis and archiving.

\section{Task 8: Geodatabase and WebGIS Website Migration}

The Project Manager will migrate a sample dataset and value-added analysis products into the Geodatabase to illustrate its capabilities and performance to the Client. The Client will be ultimately responsible for populating the Geodatabase with the existing data sets that are currently used in response to international emergencies.

\section{Task 9: Documentation and Training}

The Project Manager will develop all necessary project documentation and provide any requested training. Documentation will be delivered as a softcopy document and will be available as a hardcopy document upon request. The Project recommendations, a Geodatabase and WebGIS website design, can be implemented with minimal onsite training that will last approximately one day. Due to the limitations of the operating environment, this project can potentially introduce very little new technology during the implementation of the Geodatabase and WebGIS website. 


\subsubsection{Technology Standards}

It is beyond the scope of the Project to define the appropriate technological and institutional standards needed to implement the recommendations for the current and future requirements of humanitarian assistance organizations. This includes: "operating system standards, user interface standards, networking standards, database query standards, graphic and mapping standards, and data standards" [Tomlinson, 2003, p. 116]. Implementation of the Project's recommendations and adoption of technology standards should be conducted by the appropriate organizational authority. Consideration must be given to current and any anticipated standards that may be in effect.

\subsubsection{Risk Management}

Technology solutions, such as this project, are certainly not appropriate for all problems faced in an emergency response, but new research and applications encourage better data standards, information sharing methods, and greater equity among the humanitarian community. During a humanitarian relief operation, "many organizations do not have the capacity to access the internet at the beginning of emergency responses" [Sida and Szpak, 2004 , p. 6]. The recommendations made by this project are appropriate at a local organizational level and will require greater planning, development, and coordination for success at higher levels. New developing technologies and employee turnover in the field will challenge interoperability and contiguity of technology-based solutions.

The Geodatabase and WebGIS designs will provide the user a recommendation for how these technologies can be used for geographic information storage and distribution and illustrates only one methodology.

\subsubsection{Deliverables}

The project manager will provide the following deliverables to the client and/or any other interested organization in the international humanitarian community as outlined in the Project Proposal. The deliverables include:

- The physical Geodatabase based upon the client-approved conceptual, logical and physical design parameters.

- A sample dataset of vector and raster geographic information organized within the Geodatabase.

- An HTML-based WebGIS website design developed to provide access to the Geodatabase using an internet browser.

- Final documentation of the Geodatabase model and WebGIS website design.

- Onsite training in regard to the utilization of the Geodatabase and WebGIS website. 
- Presentation of the recommendations of the Project at the 2005 ESRI International User Conference in San Diego, CA and in Washington, DC at the request of NGA and USAID/OFDA. 


\section{Project Development}

\subsection{Geographic Data Collection and Review}

\subsubsection{Data Attributes}

The data collected during the User Needs Analysis is comprised of continuous raster data, discrete vector data, tabular data, and written documentation. The file formats include text documents, raster map products, ESRI ArcMap projects and templates, vector data, commercial satellite imagery, tabular data, and photographs (see Appendix A). For the most part, this information can be directly stored within or closely associated with the Geodatabase. Maintaining a diverse collection of information resources can be timely, but provides a user with the greatest utility in a disaster response.

\subsubsection{Vector vs. Raster}

The Geodatabase will support both vector and raster file formats for the diverse analysis requirements of the humanitarian community.

- Vector features: “A versatile and frequently used geographic data type, well suited for representing features with discrete boundaries such as wells, streets, rivers, states, and parcels" [ESRI, 2005c].

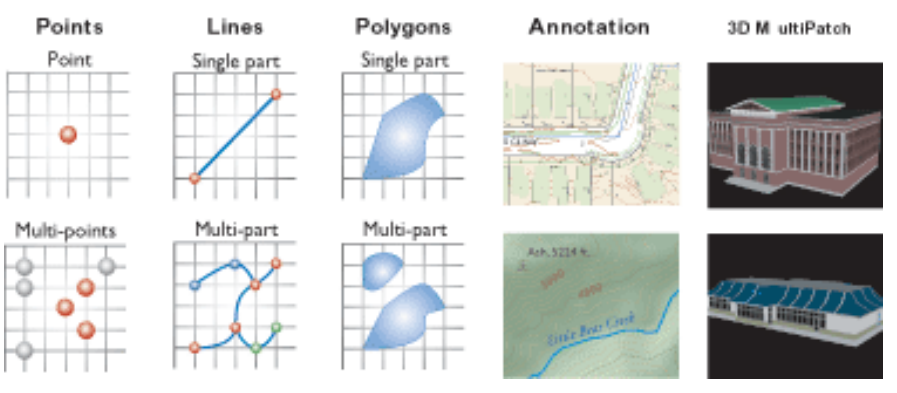

Figure 3: Vector features [ESRI, 2005c]

- Raster features: "A data type used to represent continuous layers, such as elevation, slope and aspect, vegetation, temperature, rainfall, plume dispersion, and so on. Rasters are most commonly used for the storage of aerial photographs and imagery of various kinds" [ESRI, 2005c].

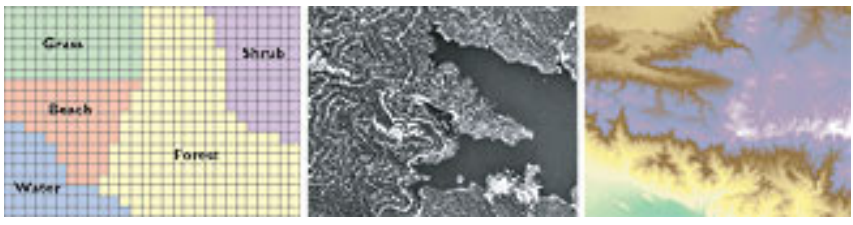

Figure 4: Raster features [ESRI, 2005c] 


\subsubsection{Scale}

The scale of the collected and shared data in the Geodatabase should not exceed 1:250,000 to avoid vector data discrepancies and inaccuracy for large-scale analysis. Although topological rules will not be enforced within the Project personal geodatabase, it is important to have data collected at similar scales to improve analysis results. In many cases, especially in undeveloped regions of the world, only small-scale regional or global data sets will be available for analysis and will exceed the preferred scale limit. Once humanitarian assistance organizations begin developing a consolidated information database, such as an enterprise GIS, collection and sharing of large-scale geographic information will increase which will improve overall quality.

\subsubsection{Quality and Error Tolerance}

The atmosphere under which humanitarian assistance organizations provide emergency response geographic data and products does not usually allow for ad hoc data quality assessments. Available data sources are reviewed and relevant information is collected to provide the necessary situational overview for first responders. Standard products like those produced by USGS, NOAA, or NGA, may have published accuracy statements and are good choices for base layers, but other thematic emergency response data sets, like damage assessments, field surveys, flight plans, and humanitarian assistance operations, will most likely not have an accuracy statement. Accuracy statements may document as many as four types of error: "referential, topological, relative, and absolute" [Tomlinson, 2003 , p. 59]. It is important for a user to determine "how much error can be tolerated in the information product [or data] and still have it be useful" [Tomlinson, 2003, p. 59]. To address the needs of first responders, the level of data quality is most commonly judged on its currency and scale and not necessarily on an error tolerance. In most cases, the quality of the data utilized in an emergency situation cannot be determined from the shared files themselves or the respective metadata.

As humanitarian assistance activities transition from the response phase to the recovery phase (see Section 1.3), a greater emphasis is placed upon building a positionally accurate, comprehensive management information system and geographic data repository. In many cases, this effort may take the form of an enterprise GIS that will be based upon the existing personal geodatabase structure. Consolidating information into an enterprise GIS will support the development of accurate and quality controlled orientation and base maps. The responsibility will most likely be addressed by a UN Humanitarian Information Centre (HIC) or local institution since they are "the best resources to produce timely and reliable information for disaster management" [AIMS Project, 2004, p. 7] and have the local knowledge to regularly update databases on land cover, land use, and socio-economic indicators. One of the best examples of this effort to maintain, update, and disseminate quality geographic information is the UNDP administered Afghanistan Information Management Service (AIMS) Project's Disaster Management Information System (DMIS) pilot project which supports stakeholders and users for decision-making in reconstruction efforts in Afghanistan. 


\subsubsection{Case Studies}

The project recommendations and data requirements have been developed from several recent international disaster response and recovery efforts (see Section 1.4.3). These case studies include the December 26, 2004 Indonesia tsunami, the January 17, 2002 Democratic Republic of Congo (DRoC) Nyiragongo volcanic eruption, the December 26, 2003 Bam, Iran earthquake, and the 2003-2004 Sahelian Africa locust emergency. A review of these events has greatly influenced the Geodatabase design and it will better satisfy future requirements.

\subsection{Geographic Database Design}

\subsubsection{Design Overview}

A geographic database, or Geodatabase, is the primary recommendation of this Project to address the current and future geographic information storage and sharing needs of a humanitarian community organization at a local level. The Geodatabase, developed by ESRI to support analysis within the ArcGIS software platform, provides users with a diverse RDBMS access and storage architecture and application environment. Utilizing the personal geodatabase or enterprise GIS architecture, a user can develop customized geographic data storage solutions. The Geodatabase design environment additionally promotes efficient, accurate, and controlled data organization through the implementation of coded value domains and subtypes.

\subsubsection{Geodatabase Terms}

- Relational Database Management System (RDBMS): A relational database management system is a database management system that is based on the relational model as introduced by Edgar F. Codd in his seminal paper $A$ Relational Model of Data for Large Shared Data Banks [Codd, 1970]. Fundamentally, these systems must "present the data to the user as relations (a presentation in tabular form, i.e. as a collection of tables with each table consisting of a set of rows and columns, can satisfy this property) and provided relational operators to manipulate the data in tabular form" [Codd, 1970]. All elements of a geodatabase are stored in an RDBMS; including the schema and rule base for each geographic data set as well as the actual spatial and attribute data.

- Personal Geodatabase: "Uses the Microsoft Jet Engine database file structure to persist GIS data and is much like file-based workspaces and hold databases up to 2 GB in size. Personal geodatabases are ideal for working with smaller data sets for GIS projects and in small work-groups. Typically, users will employ multiple personal geodatabases for their data collections and access these simultaneously for their GIS work" [ESRI, 2005c]. Personal geodatabases support single user editing and "have all the functionality of a multiuser geodatabase, except for versioning" [Zeiler, 1999, p. 13]. 
- Multiuser Geodatabase: "Requires the use of ArcSDE and works with a variety of RDBMS storage models (IBM DB2, Informix, Oracle - both with and without Oracle Spatial, and Structured Query Language (SQL) Server). Multiuser geodatabases [enterprise GIS] are primarily used in work group, department, and enterprise settings. Multiuser geodatabases readily scale to extremely large sizes and numbers of users. Through many large geodatabase implementations, ESRI has found that RDBMSs are efficient at moving the type of large binary objects required for GIS data in and out of tables" [ESRI, 2005c]. An enterprise GIS supports version management and allows many editors to work concurrently.

\subsubsection{Architecture}

"Geodatabases work across a range of RDBMS architectures, come in many sizes, and have varying numbers of users. They can scale from smaller, single user databases built on the Microsoft Jet Engine (Microsoft Access) database up to larger work group, department, and enterprise databases accessed by many users" [ESRI, 2005c]. Two types of geodatabase implementations are currently available from ESRI: personal geodatabases and multiuser or enterprise geodatabases. "The geodatabase is a multi-tier architecture (application and storage), where aspects related to data storage and retrieval are implemented in the storage (RDBMS) tier as simple tables, while high-level data integrity and information processing functions are retained in the application software (GIS)" [ESRI, 2005c].

\subsubsection{RDBMS Storage}

"RDBMSs provide a simple, formal data model for storing and working with information in tables. RDBMSs are simple and flexible because their generic relational data model enables them to support a broad array of applications" [ESRI, 2005c]. Storage within a RDBMS is based upon the following information system concepts: [ESRI, 2005c]

- Data is organized into tables.

- Tables contain rows.

- All rows in a table have the same columns.

- Each column has a type such as integer, decimal number, character, date, etc.

- Relationships are used to associate rows from one table with rows in another table. This is based on a common column in each table, often called the 'primary key' and the 'foreign key'."

- Relational integrity rules exist for table-based data sets. For example, each row always shares the same columns, a domain lists the valid values or value ranges for a column, and so on.

- SQL, a command language of functions and operators, is available to operate on the tables and their data elements. 
- The SQL operators are designed to work with the generic relational data types such as integers, decimal numbers, and characters.

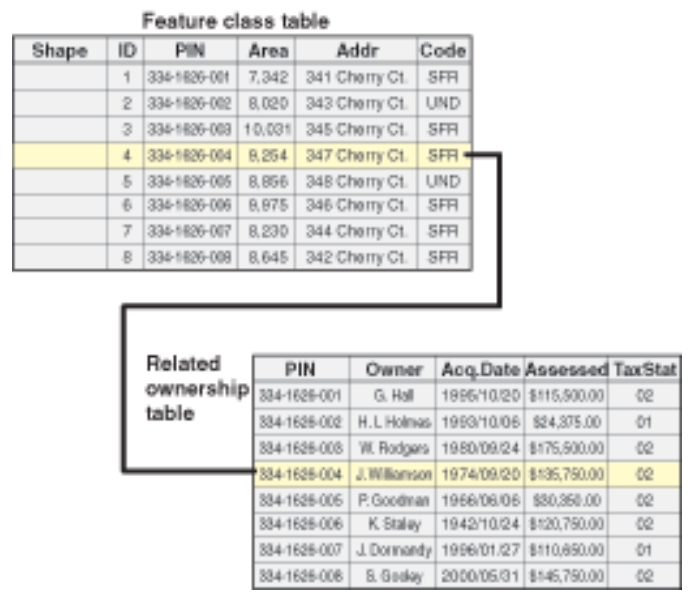

Figure 5: Geodatabase data table relationships [ESRI, 2005c]

\subsubsection{ESRI Geodatabase Overview}



Figure 6: ESRI Geodatabase and ArcGIS Products [ESRI, 2005c] 


\section{Project Geodatabase Design}

\subsection{Solution Proposal Overview}

The personal geodatabase model has been selected to illustrate the utility of a relational database for storing and sharing geographic information in an efficient and intuitive manner. The Geodatabase will serve as a proof of concept application for a local department-level GIS application and can be expanded in the future using ESRI's ArcSDE software to develop a more robust and versatile multi-department enterprise system. ArcSDE provides "remote access to geographic data and allows many users to view and edit the same geographic data" [Zeiler, 1999, p. 12]. A department-level application "supports at least one important ongoing business function inside an organization" [Tomlinson, 2003, p. 5], in this case, OFDA's disaster response function. A future enterprise-wide system will "allow the organization's members to access and integrate [the Geodatabase] across all departments" [Tomlinson, 2003, p. 6], or in this case, several departments within a humanitarian organizations.

In the context of this Project, the Geodatabase provides several distinct advantages that include:

- The personal geodatabase is compact and deployable,

- Coded value domains and subtypes improve functionality and efficiency (e.g. data creation, organization, and attribute maintenance),

- Predetermined attribute values reduce error and increase standardization,

- A record of institutional knowledge base.

A Geodatabase can add needed "analytical capacity to the information management capacity" [Sida and Szpak, 2004, p. 6] to support decision-making in emergency response and recovery operations and encourage information sharing between humanitarian assistance organizations. Additionally, the Geodatabase supports a "portable information environment" [Meissner et al., 2002, p. 3] as recommended in emergency response situations.

The geographic data that will form the framework of the Geodatabase can be organized into three fundamental data sets for emergency management that include:

- "Natural hazards information: denotes the presence and effect of natural phenomena.

- Information on natural ecosystems: provides the basis for estimating the effect natural hazards can have on the goods and services these systems offer and also determines the factors or conditions that create, modify, accelerate, and/or retard the occurrence of a natural event. 
- Information on population and infrastructure: basis for quantifying the impact natural events can have on existing and planned development activities" [OAS, 1990].

Utilizing this organization to develop the conceptual, logical, and physical models will help the humanitarian assistance organization address current and future data needs.

\subsection{Geodatabase Design Process}

The geographic database design process has been summarized in ten general steps (see Figure 7). This process has been used to develop the Project's Geodatabase framework through the conceptual, logical, and physical model design stages. The geodatabase model is "the bridge between people's cognitive perception of the objects surrounding them in the world and how those objects are stored in relational database" [Zeiler, 1999, 16]. The design phases are elaborated upon in greater detail in the following sections.

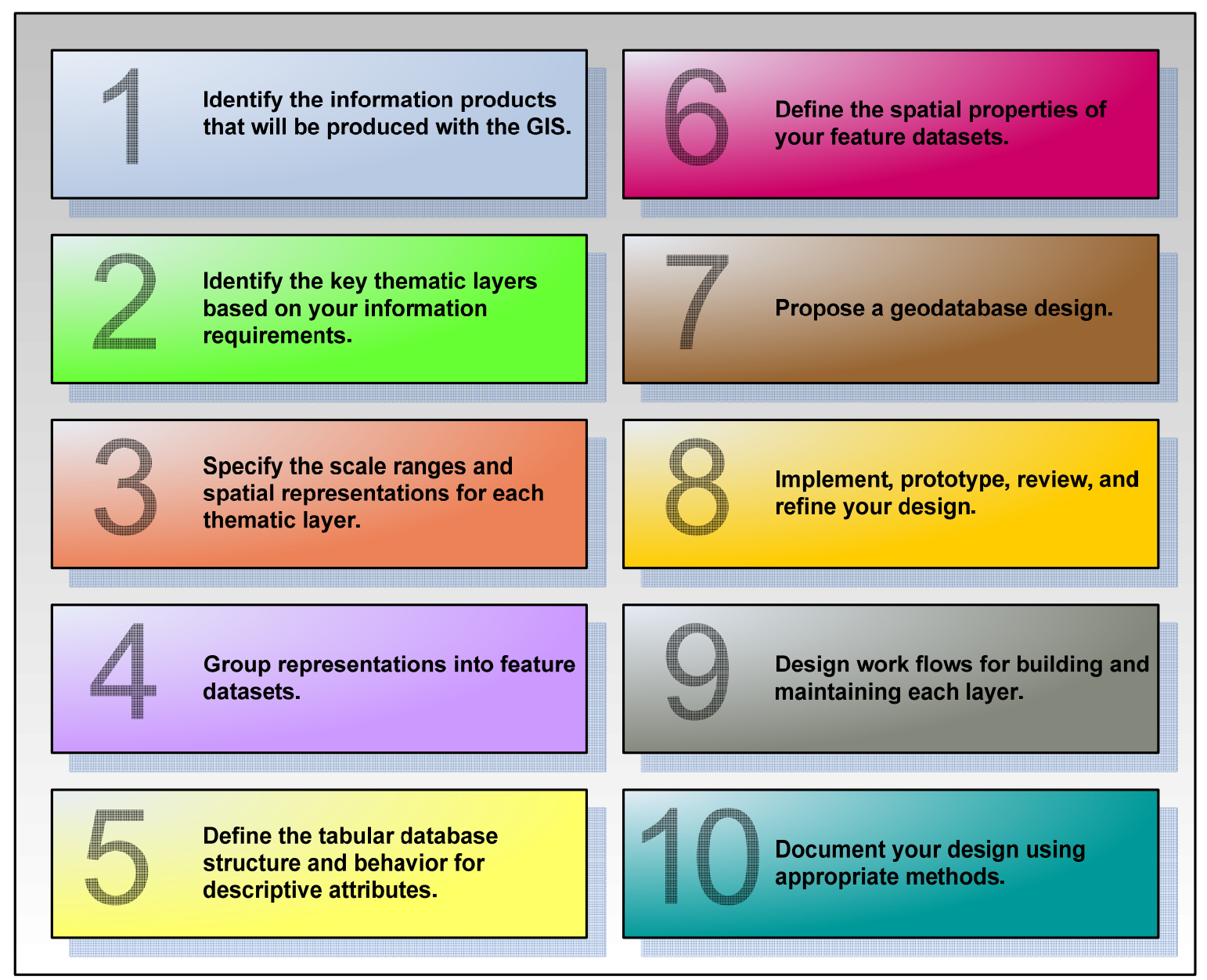

Figure 7: Geodatabase Design Process [Arctur and Zeiler, 2004, p. 9] 


\subsection{Conceptual Model}

\subsubsection{Conceptual Model Overview}

The conceptual model phase of the design process "involves all the pre-planning and business activities and identifies the applications that the [Geodatabase] must support" [ESRI, 2004, p. 3-10]. The conceptual model is an "analysis tool for understanding the problem" [ESRI, 2004, p. 4-4] and it identifies the general thematic categories of data needed for the functionality of the Geodatabase applications. The thematic categories will eventually be organized into geographic layers, tables, attributes, and relationships. The Geodatabase provides a sampling of data sets that could be utilized in an emergency response.

\subsubsection{Conceptual Model Terms}

- Concept: A concept is "any real-world idea, thing, person, place, or other entity of interest to the client in the current problem" [ESRI, 2004, p. 4-6]. In the project definition, concepts are usually nouns and noun phrases and have their own attributes.

- Attribute: An attribute is information describing a map feature and can be nouns or adjectives in the project definition. Since the emphasis in the conceptual model is "understanding structural relationships," [ESRI, 2004, p. 4-12], many attributes will not necessarily need to be identified.

- Relationships: Relationships and associations, which are connections between concepts, are usually found as verbs and transitive verbs in the project definition.

\subsubsection{Conceptual Model Design}

\subsubsection{Information Products}

The Geodatabase could potentially be deployed by an OFDA DART to support disaster response and recovery operations being organized by the UN or other IOs. These firstresponder operations are most commonly composed of assessment teams that visit areas affected by the natural disaster and report the observed damages such as "destroyed houses, agricultural land lost, livestock dead, number of people dead, injured, or made homeless, canals/irrigation schemes, and roads destroyed." [AIMS Project, 2004, p. 4] Information products developed from the geographic data stored in the Geodatabase should reflect the current observations from the assessment teams and the dynamic requirements from other humanitarian assistance organizations. Examples of these information products include:

- W3: Who? What? Where? (Resource tracking and allocation)

- Affected populated places 
- Affected population statistics/demographics

- Administrative boundaries

- Critical facilities/infrastructure mapping

- Multiple hazard mapping

- Orientation base map

- Image maps (satellite imagery and/or aerial photography)

- Locations of Internally Displaced Persons (IDPs)/Refugees

\subsubsection{Key Thematic Layers}

The key thematic layers identified are based upon the base layers outlined in the Data Requirements of the User Needs Analysis (see Section 1.4.5). The list is not exhaustive but communicates an understanding of the intended applications and needs of the user.

- Administrative

- Building

- Emergency Response

- Physical Environment

- Transportation

- Utilities

\subsection{Logical Model}

\subsubsection{Logical Model Overview}

The logical model is a "specification for the database schema and is more detailed than the conceptual model" [ESRI, 2004, p. 3-10]. The key task in developing a logical model is "to precisely define the set of objects of interest and to identify the relationships between them" [Zeiler, 1999, p. 16].

\subsubsection{Logical Model Terms}

- Feature Class: "A collection of geographic features with the same geometry type (such as point, line, or polygon), the same attributes, and the same spatial reference." [ESRI, 2005d] Feature classes can stand alone within a geodatabase or grouped within feature datasets.

- Feature Dataset: "A collection of feature classes stored together that share the same spatial reference; that is, they have the same coordinate system, and their features fall within a common geographic area." [ESRI, 2005d] Additionally, "the associated topology and network objects that bind them are also included" [Arctur and Zeiler, 2004, p. 6]. 


\subsubsection{Logical Model Design}

\subsubsection{Feature Classes and Raster Datasets}

The following information in Tables 2 and 3 illustrates how the feature classes and raster datasets in the Geodatabase can be described in a more detailed manner than the Conceptual Model. Categories such as the associated scale range or thematic relationship are sometimes scale-dependent and may vary throughout the design of the Geodatabase.

Table 2: Logical Model Feature Classes

\begin{tabular}{|c|c|c|c|c|c|}
\hline \multirow{2}{*}{ Feature Class } & \multicolumn{3}{|c|}{ Relative Scale Ranges } & \multirow{2}{*}{ Key Thematic Layer } & \multirow{2}{*}{ Feature Dataset } \\
\hline & Small & Medium & Large & & \\
\hline Administrative boundaries & $X$ & & & Administrative & Administrative \\
\hline Airports/runways & & $\mathrm{X}$ & & Transportation & Infrastructure \\
\hline Disaster information (current) & & & $\mathrm{X}$ & Emergency Response & Emergency Response \\
\hline $\begin{array}{l}\text { Disaster information } \\
\text { (historical) }\end{array}$ & & & $\mathrm{X}$ & Emergency Response & Natural Disasters \\
\hline Fire departments & & $\mathrm{X}$ & & Building & Infrastructure \\
\hline Forests & $\mathrm{X}$ & & & Physical Environment & Environment \\
\hline Geology & $\mathrm{X}$ & & & Physical Environment & Geo-Environment \\
\hline Geophysical & $\mathrm{X}$ & & & Physical Environment & Geo-Environment \\
\hline Hospitals/health facilities & & $\mathrm{X}$ & & Building & Infrastructure \\
\hline $\begin{array}{l}\text { Hydrography (rivers, streams, } \\
\text { lakes) }\end{array}$ & $\mathrm{X}$ & & & Physical Environment & Environment \\
\hline Hypsography (point elevation) & $\mathrm{X}$ & & & Physical Environment & Raster \\
\hline Police departments & & $\mathrm{X}$ & & Building & Infrastructure \\
\hline Population centers & $\mathrm{X}$ & & & Demographic & Administrative \\
\hline Railroads & & $\mathrm{X}$ & & Transportation & Infrastructure \\
\hline Religious centers & & $\mathrm{X}$ & & Building & Infrastructure \\
\hline Roads & & $\mathrm{X}$ & & Transportation & Infrastructure \\
\hline Schools & & $\mathrm{X}$ & & Building & Infrastructure \\
\hline Soils & $\mathrm{X}$ & & & Physical Environment & Environment \\
\hline Utility Lines & & $\mathrm{X}$ & & Infrastructure & Infrastructure \\
\hline $\begin{array}{l}\text { Water sources (potable/non- } \\
\text { potable) }\end{array}$ & & $\mathrm{X}$ & & Physical Environment & Infrastructure \\
\hline Watershed delineation & $\mathrm{X}$ & & & Physical Environment & Environment \\
\hline Weather (historical) & $\mathrm{X}$ & & & Physical Environment & Environment \\
\hline
\end{tabular}


Table 3: Logical Model Raster Datasets

\begin{tabular}{|l|l|}
\hline \multicolumn{1}{|c|}{ Raster Dataset } & \multicolumn{1}{c|}{ Resolution } \\
\hline Aerial photography & $>1$-foot \\
\hline $\begin{array}{l}\text { Moderate-resolution civil satellite imagery } \\
\text { (Landsat, MODIS, ASTER) }\end{array}$ & 30 -meter \\
\hline $\begin{array}{l}\text { High-resolution commercial satellite imagery } \\
\text { (Quickbird, Ikonos, ORBIMAGE) }\end{array}$ & $>1$-meter \\
\hline Low-resolution DEM (GTOPO30) & 30 arc-second / 1-kilometer \\
\hline Moderate-resolution DEM (DTED0 or DTED1) & 100 -meter or 30-meter \\
\hline High-resolution DEM (LIDAR) & $\geq 0.75$-meter \\
\hline Land cover/land use, AVHRR & 1 -kilometer \\
\hline Population density & 2.5 arc-minute \\
\hline Population distribution & 30 arc-second / 1-kilometer \\
\hline
\end{tabular}

\subsection{Physical Model}

\subsubsection{Physical Model Overview}

The physical model has been built from the logical model and is ready for implementation, prototyping, review, refinement, and deployment. The physical model's schema has been "tested for functionality and performance during the QA/QC process" [ESRI, 2004, p. 3-11] (see Appendix F).

\subsubsection{Physical Model Terms}

- Coded Value Domain: "A type of attribute domain that defines a set of permissible values for an attribute in a geodatabase." [ESRI, 2005d] A coded value domain name consists of an integer code and its description or equivalent value in the geodatabase. Codes are stored in the database properties of the geodatabase, and corresponding values appear in the attribute table. A coded value domain can be applied to text, short-integer, long-integer, float, double, and data attribute values.

- Subtype: "A subset of features in a feature class or objects in a table that share the same attributes." [ESRI, 2005d] Subtypes categorize "attribute values within a single field in any geodatabase feature class or table" [Taggart, 2000, p. 38].

\subsubsection{Physical Model Design}

The design and implementation of the Geodatabase are the fundamental concepts of this Project's recommendations. Utilizing the functionality of coded value domains and subtypes a user can more accurately ensure data consistency and improve data organization. The key motivation for using subtypes is performance because "they let you control the specific behavior for a set of features in a feature class through attribute rules, default values, connectivity rules, and relationship rules." [Zeiler, 1999, p. 80] Emergency responders can speed up data entry and benefit from the stored knowledge base already built into the Geodatabase from the originating humanitarian organization. 


\subsubsection{Geodatabase Spatial Reference}

The spatial reference of the Geodatabase and all imported information will be:

- Coordinate system: Geographic Coordinate System (GCS)

- Datum: WGS 1984

- Projection: Plate Carree

\subsubsection{Geodatabase Schema}

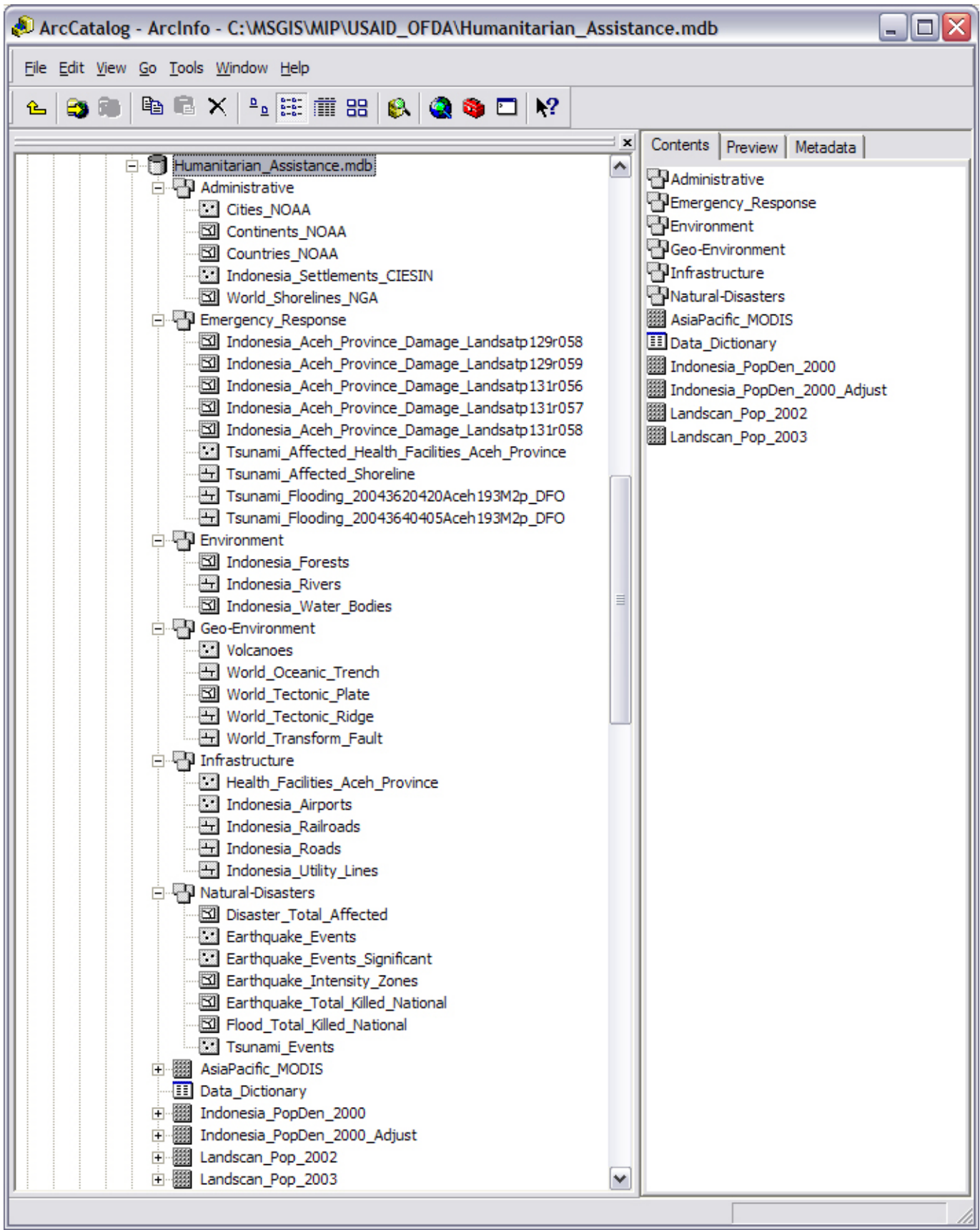

Figure 8: Geodatabase schema example in ESRI ArcCatalog 


\subsubsection{Geodatabase Coded Value Domains}

Coded value domains can potentially be applied to all feature classes and feature datasets in the Geodatabase. For the purpose of this project, three geodatabase coded value domain examples were created to demonstrate the functionality of the domain in regard to data creation, organization, and maintenance. These domains include: SOURCE_ID (see Table 4), EMER_TYPE (see Table 5), and MAGNITUDE (see Table 6) and provide the user with a list of valid values to select from. The values used for the SOURCE_ID and EMER_TYPE domains are lists of examples of some of the most common classifications in these categories but are not exhaustive. The values used for the MAGNITUDE domain are based upon the classifications established by the USGS Earthquake Hazards Program [USGS, 2005]. In all cases, the coding scheme allows for future additions.

Table 4: Example of a Data Source Coded Value Domain Schema

\begin{tabular}{|c|c|}
\hline Coded value domain \\
SOURCE_ID \\
Description Data source coded \\
Field type value domain \\
Split policy Short integer \\
Merge policy Default value & \\
\hline Code & \\
\hline 1 & \\
2 & Description \\
3 & USAID \\
4 & USGS \\
5 & NOAA \\
6 & NASA \\
7 & CIA \\
8 & NGA \\
9 & FEMA \\
10 & USG \\
11 & ORNL \\
12 & CIESIN \\
13 & DFO \\
14 & CRED \\
15 & Data Repository of the GIST \\
16 & UT Institute for Geophysics \\
17 & ESRI \\
18 & NGO \\
19 & UNEP \\
20 & UNDP \\
21 & UNICEF \\
22 & WFP \\
999 & WHO \\
& ICRC \\
& Other \\
\hline
\end{tabular}


Table 5: Example of an Emergency Type Coded Value Domain Schema

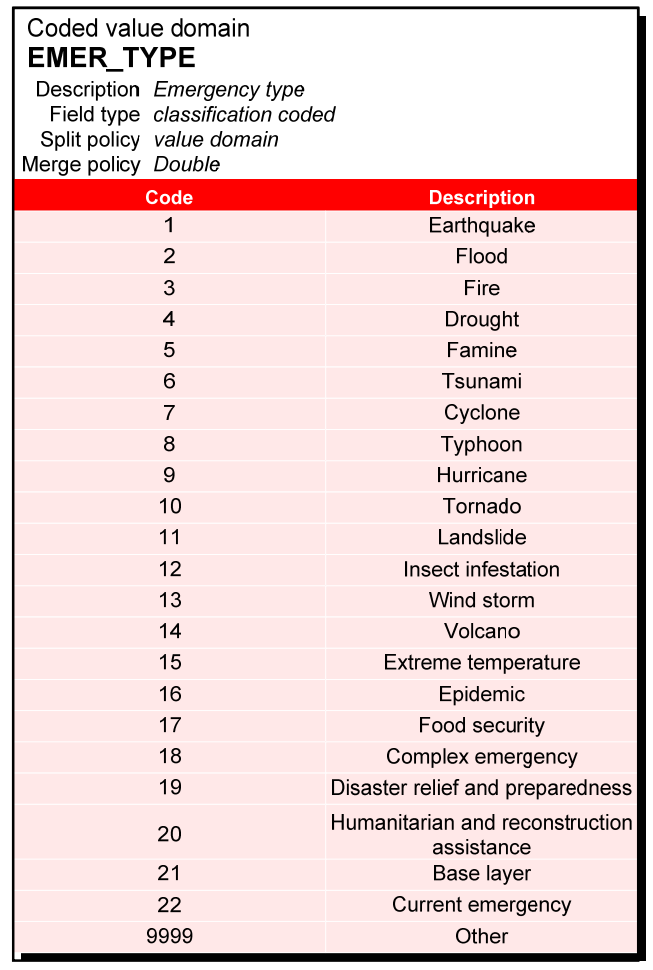

Table 6: Example of an Earthquake Magnitude Coded Value Domain Schema

\begin{tabular}{|cc|}
\hline Coded value domain \\
MAGNITUDE \\
Description USGS earthquake \\
Field type classification coded \\
Split policy value domain \\
Merge policy Double \\
\hline Code \\
\hline $2.0-2.9$ & \\
$3.0-3.9$ & Description \\
$4.0-4.9$ & VERY MINOR \\
$5.0-5.9$ & MINOR \\
$6.0-6.9$ & LIGHT \\
$7.0-7.9$ & MODERATE \\
$8.0-9.9$ & STRONG \\
& MAJOR \\
\hline
\end{tabular}




\subsubsection{Feature Class Attribute Subtypes}

Subtypes can potentially be applied to all feature classes and feature datasets in the Geodatabase. For the purpose of this project, five feature class subtype examples were created to demonstrate the functionality of the subtype in regard to data creation, organization, and maintenance of feature class attributes. These subtypes are based upon accepted operational coding standards, but can be designed for any system configuration. These subtypes include AEPTTYPE (airport type), RRLNTYPE (railroad line type), RDLNTYPE (road line type), UTLNTYPE (utility line type), and ZONE_ (earthquake intensity zone type).



Figure 9: Example of an Airport Subtype Schema 


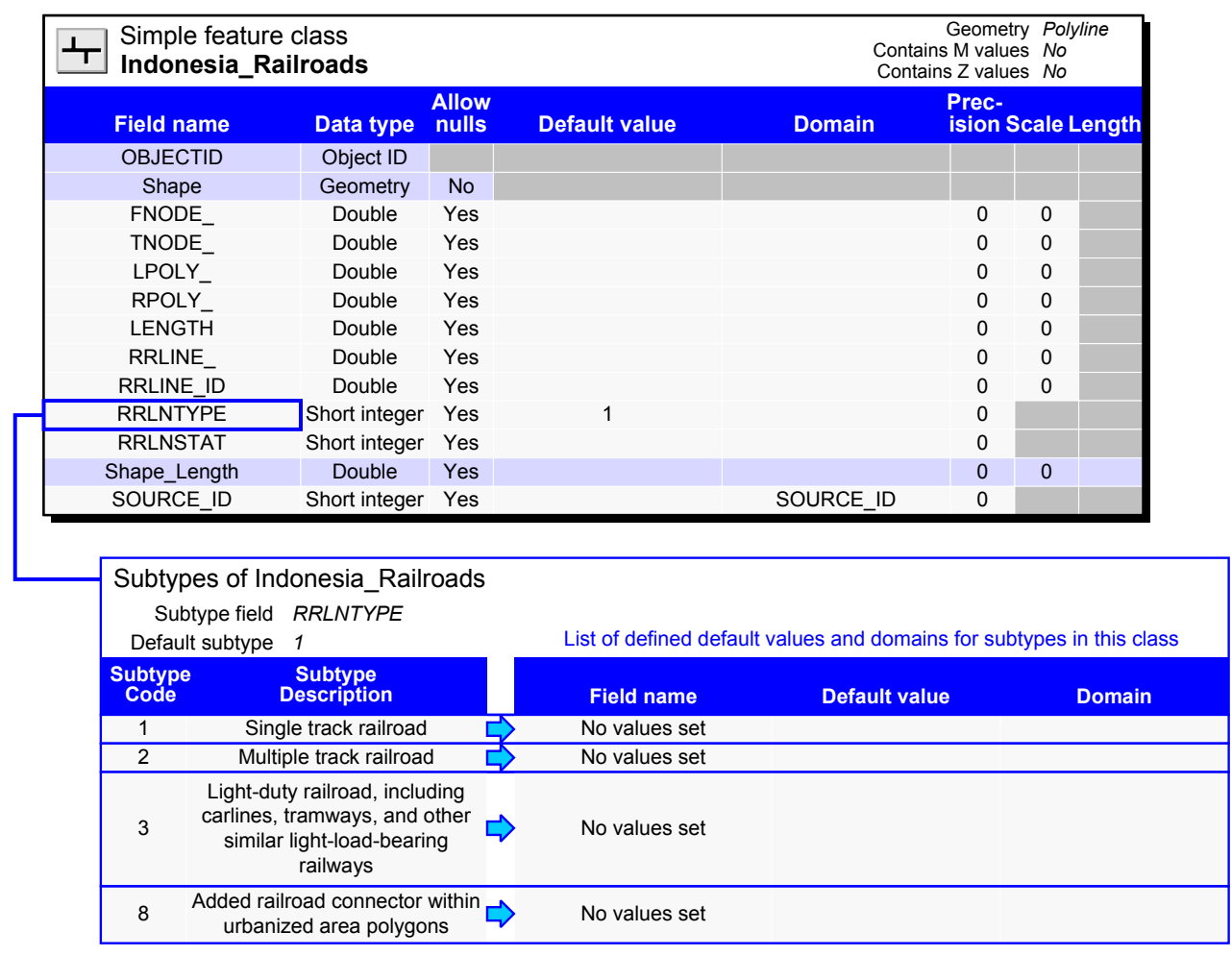

Figure 10: Example of a Railroad Subtype Schema

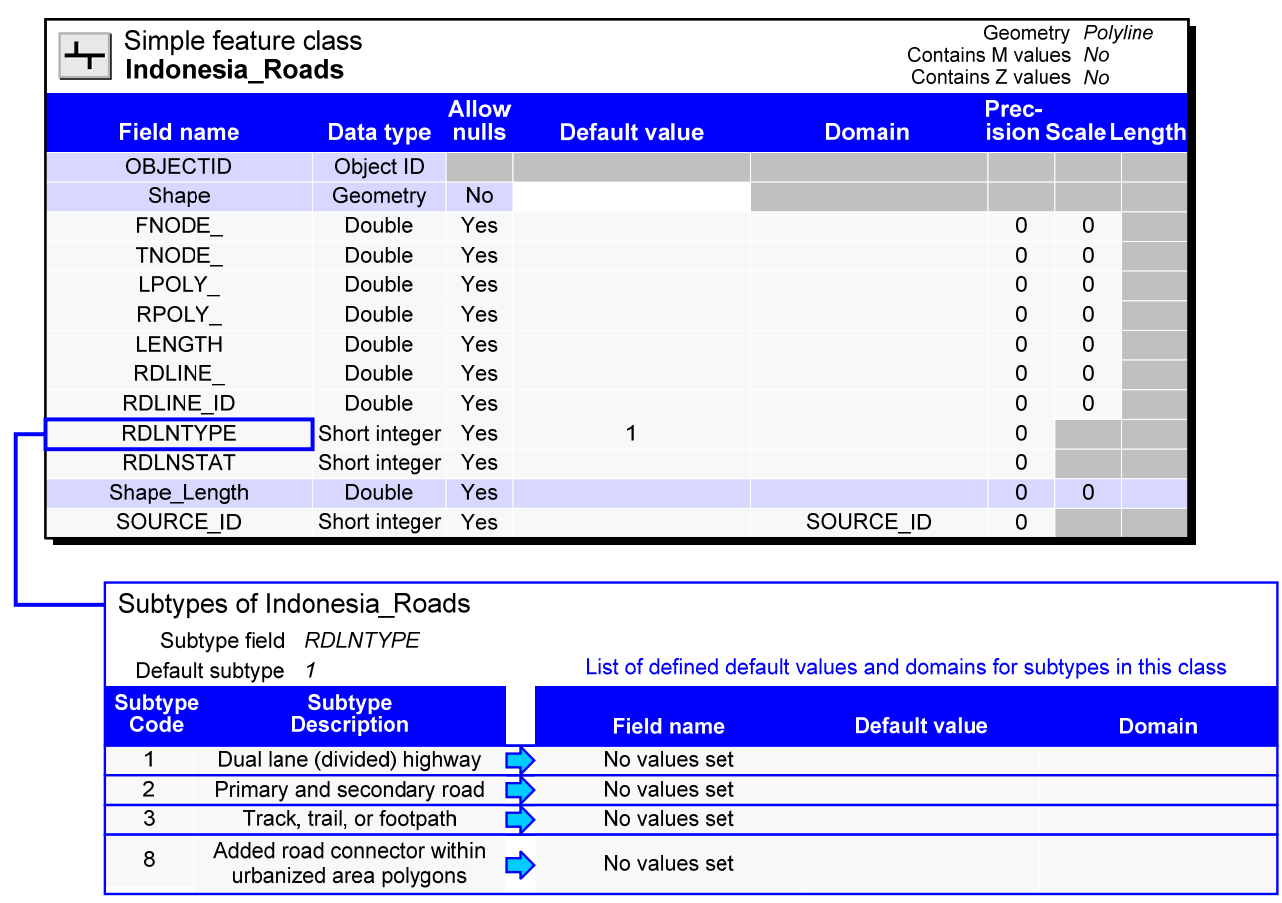

Figure 11: Example of a Road Subtype Schema 


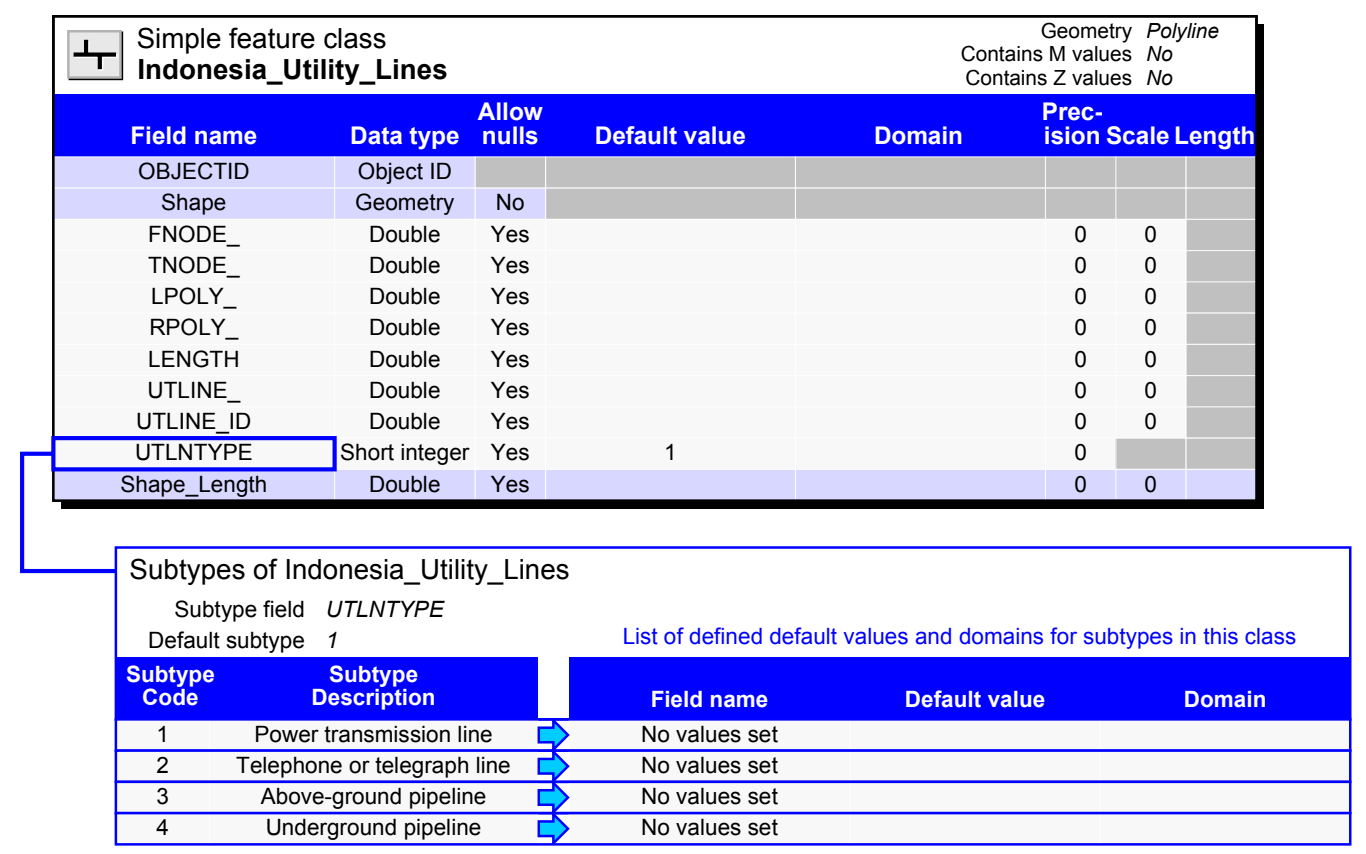

Figure 12: Example of a Utility Line Subtype Schema

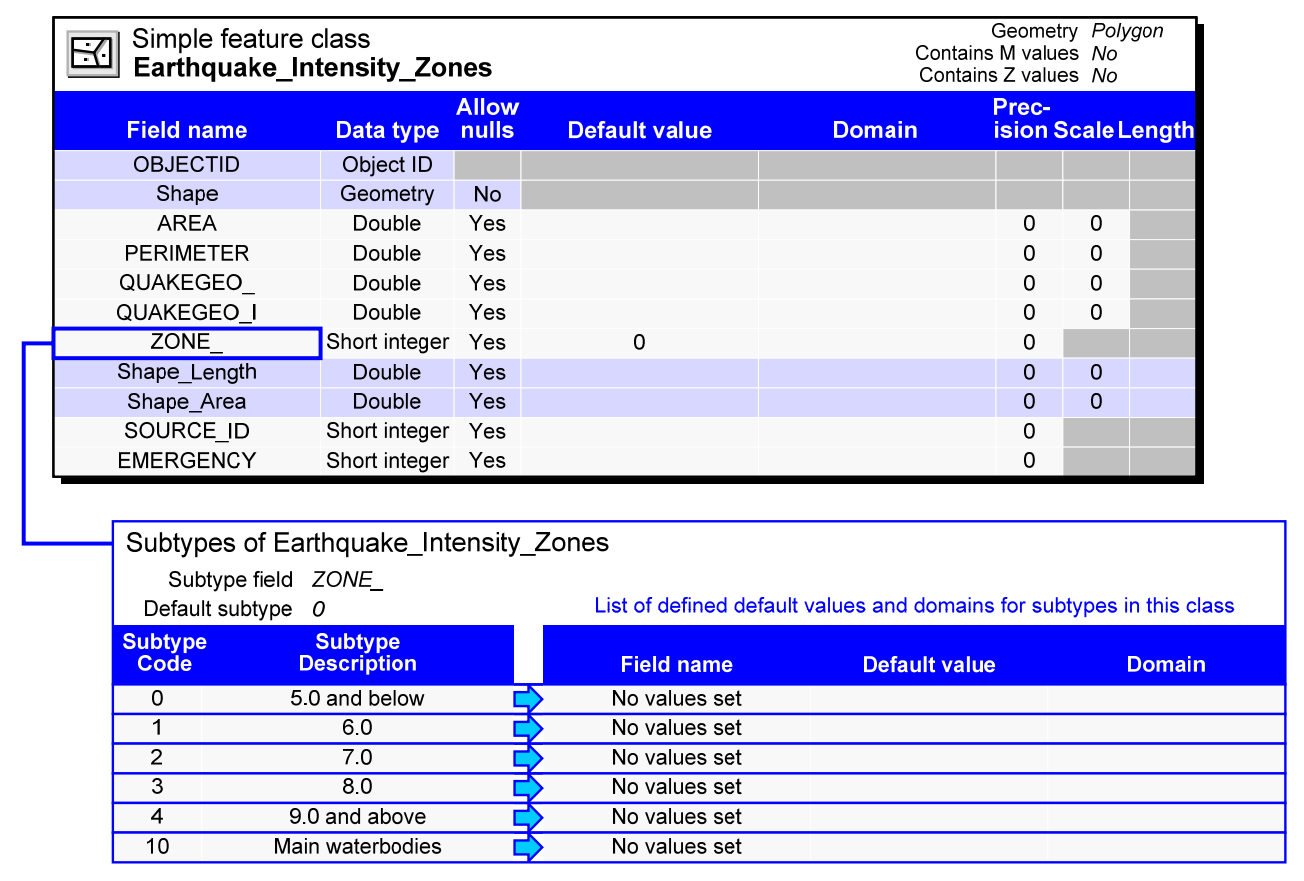

Figure 13: Example of an Earthquake Intensity Zone Subtype Schema 


\subsection{Geodatabase Data Dictionary}

A data dictionary is the file that defines the basic organization of an aspect of the database. This file is often hidden from users by the database management system "to prevent them from accidentally destroying its contents." [Webopedia Data Dictionary, 2005] The data dictionary serves as a repository for information about the feature classes and raster datasets and exists in the Geodatabase as a nonspatial database table called DATA_DICTIONARY. "This information is used to create the connection between the data dictionary and the datasets and can be used to automate the data ingest and update process." [Cartwright and Habermann, 2000] "Data dictionaries do not contain any actual data from the database, only book-keeping information for managing it" [Webopedia Data Dictionary, 2005].

One important application of the data dictionary is to provide access to a glossary of the predetermined emergency type values that exist in the Geodatabase. It holds the definitions and valid values of which feature classes and raster datasets are assigned to what emergency type. Using the WebGIS website application, a user can instantly query and activate the data layers associated with a specific emergency type of interest (see Figure 14). This will provide greater efficiency for generating a thematic map than a traditional metadata server that usually only searches for specific attribute values, resulting in a potentially disorganized and voluminous selection. An emergency type thematic query allows an emergency response knowledge base to be predefined within the Geodatabase and presented easily to an end user (see Figures 19-22).

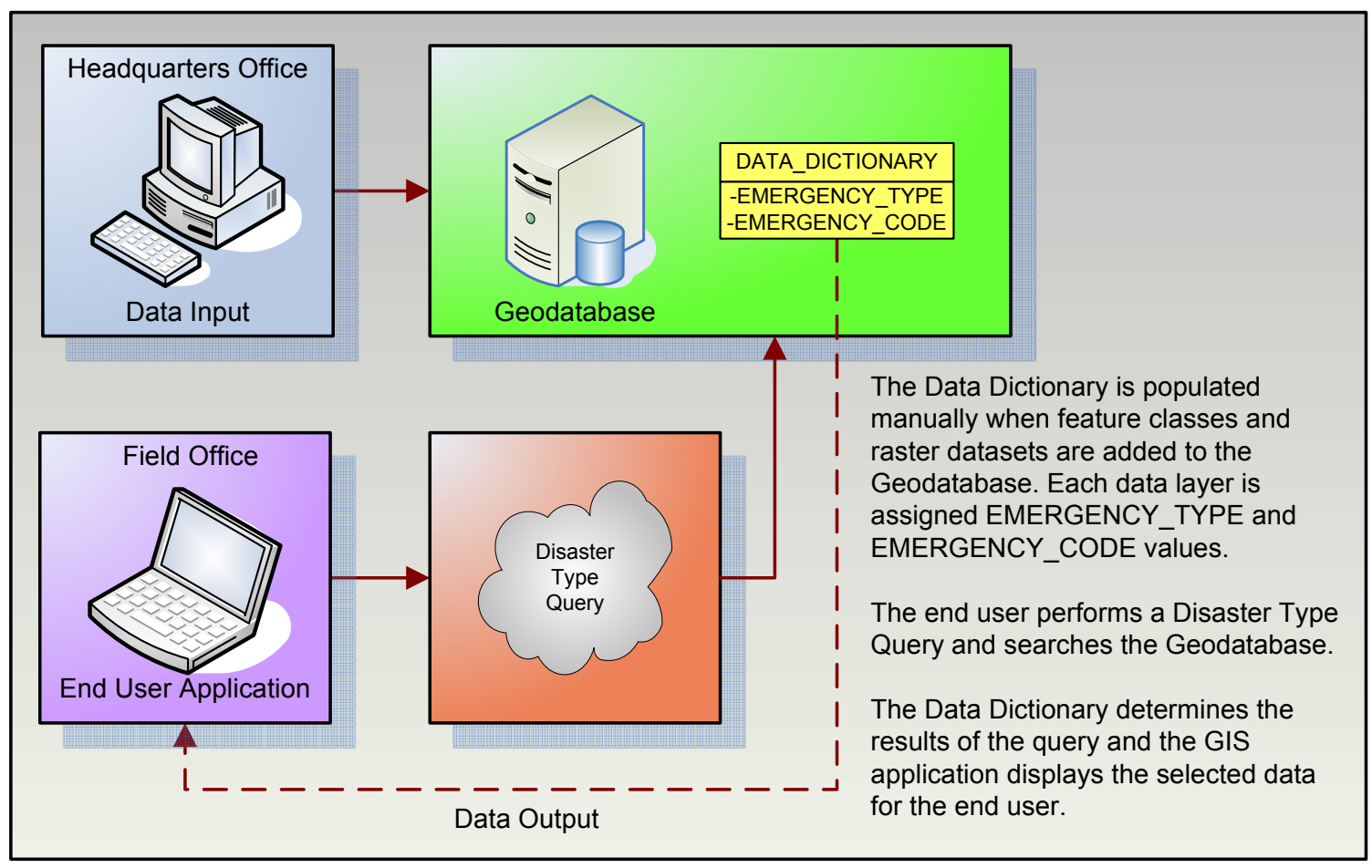

Figure 14: Data Dictionary Application 


\subsubsection{Data Dictionary Thematic Layers}

The literature review that was conducted during the course of this Project revealed very little evidence that organizations coordinate thematic data layer standards for analysis and map production within the humanitarian community. The standards of most thematic products are generated at the discretion of the analyst and/or organization and require significant data maintenance efforts over time. It is the recommendation of the Project Manager that the designed Geodatabase proof-of-concept illustrate how the Emergency Classification coded value domain (EMER_TYPE) can be used within a WebGIS application to expedite the thematic map creation process. The Geodatabase Data Dictionary has been initially based upon the www.HazardMaps.gov website data layer organization developed by FEMA for the United States (see Table 7).

Table 7: FEMA HazardMaps.gov Thematic Layers [FEMA, 2005]

\begin{tabular}{|l|l|}
\hline Thematic Map & \multicolumn{1}{c|}{ Data Layers } \\
\hline Base & $\begin{array}{l}\text { Cities, Streets, Administrative Boundaries, Land Cover, } \\
\text { Populated Areas }\end{array}$ \\
\hline Earthquake & $\begin{array}{l}\text { Current earthquake, Earthquake historical events, Peak ground } \\
\text { acceleration, DOQQ }\end{array}$ \\
\hline Flood & $\begin{array}{l}\text { Base flood elevations, Historical flood data, Flood hazard } \\
\text { areas, DOQQ }\end{array}$ \\
\hline Hurricane & Storm/depression/hurricane track \\
\hline Landslide & Landslide historical events, Landslide susceptibility, DEM \\
\hline Tornado & Tornado historical events \\
\hline Tsunami & Tsunami run-up events, Tsunami evacuation planning \\
\hline Volcano & Volcanoes \\
\hline Wind & Wind, 100-year exposure \\
\hline
\end{tabular}




\subsubsection{Data Dictionary Diagram}

The Data Dictionary Diagram (see Figure 15) is a simplified Unified Modeling Language (UML) diagram based upon the Geodatabase Object Model diagram [ESRI, 2005b]. This data model "highlights the key geodatabase data access objects" [Zeiler, 1999, p. 98] and is developed using a computer-aided software engineering (CASE) environment. The purpose of this diagram is to illustrate the relationship the DATA_DICTIONARY table has with the rest of the Geodatabase tables and what information is accessed during a thematic query. The DATA_DICTIONARY table will store the predetermined relationships between geodatabase feature classes (ObjectClassID) and the EMER_TYPE coded value domain (CodedValues) for display in a GIS application (see Table 8).



Figure 15: Data Dictionary and Selected Geodatabase System Tables 
The DATA_DICTIONARY table will be updated manually as new feature classes and feature datasets are added to the Geodatabase. The process can be automated in the future by developing a customized graphic user interface that allows a user to assign an emergency type domain value to the feature class or feature dataset when importing into the Geodatabase, automatically updating the DATA_DICTIONARY table. Currently, the EMER_TYPE coded value domain is assigned to the CodedValues table field which will assure data input accuracy, consistency, and efficiency (see Figure 15).

\section{Table 8: Geodatabase Data Dictionary}

\section{ObjectClassID}

CodedValues

DISASTER_TOTAL_AFFECTED

EARTHQUAKE_EVENTS

EARTHQUAKE_EVENTS_SIGNIFICANT

EARTHQUAKE_INTENSITY_ZONES

EARTHQUAKE_TOTAL_KILLED NATIONAL

VOLCANOES

WORLD_OCEANIC_TRENCH

WORLD_TECTONIC_FAULT

WORLD_TECTONIC_PLATE

WORLD_TECTONIC_RIDGE

DISASTER_TOTAL_AFFECTED

FLOOD_TOTAL_KILLED_NATIONAL

DISASTER TOTAL_AFFECTED

FOREST_FIRE_EXTENT

GLOBAL_BURNT_AREA_ASIAPACIFIC

INDONESIA_FORESTS

DISASTER_TOTAL_AFFECTED

DISASTER_TOTAL_AFFECTED

EARTHQUAKE_EVENTS

EARTHQUAKE_EVENTS_SIGNIFICANT

EARTHQUAKE_INTENSITY_ZONES

EARTHQUAKE_TOTAL_KILLED_NATIONAL

TSUNAMI_EVENTS

WORLD_OCEANIC_TRENCH

WORLD_TECTONIC_FAULT

WORLD_TECTONIC_PLATE

WORLD_TECTONIC_RIDGE

DISASTER_TOTAL_AFFECTED

DISASTER_TOTAL_AFFECTED

INDONESIA FORESTS

DISASTER_TOTAL_AFFECTED

DISASTER_TOTAL_AFFECTED

VOLCANOES

DISASTER_TOTAL_AFFECTED

CITIES_NOAA

CONTINENTS_NOAA

COUNTRIES_NOAA

HEALTH_FACILITIES_ACEH_PROVINCE

INDONESIA AIRPORTS

INDONESIA_RAILROADS

INDONESIA_RIVERS

\begin{tabular}{|l|}
\hline CodedValues \\
\hline 1 \\
\hline 1 \\
\hline 1 \\
\hline 1 \\
\hline 1 \\
\hline 1 \\
\hline 1 \\
\hline 1 \\
\hline 1 \\
\hline 2 \\
\hline 2 \\
\hline 3 \\
\hline 3 \\
\hline 3 \\
\hline 3 \\
\hline 4 \\
\hline 6 \\
\hline 6 \\
\hline 6 \\
\hline 6 \\
\hline 6 \\
\hline 6 \\
\hline 6 \\
\hline 6 \\
\hline 6 \\
\hline 6 \\
\hline 11 \\
\hline 12 \\
\hline 12 \\
\hline 13 \\
\hline 14 \\
\hline 14 \\
\hline 21 \\
\hline 21 \\
\hline 21 \\
\hline \\
\hline 21 \\
\hline 15 \\
\hline 1 \\
\hline 1 \\
\hline 1 \\
\hline 1 \\
\hline 1 \\
\hline 1 \\
\hline 1 \\
\hline
\end{tabular}




\begin{tabular}{|l|l|}
\hline ObjectClassID & CodedValues \\
\hline INDONESIA_ROADS & 21 \\
\hline INDONESIA_SETTLEMENTS_CIESIN & 21 \\
\hline INDONESIA_UTILITY_LINES & 21 \\
\hline INDONESIA_WATER_BODIES & 21 \\
\hline WORLD_SHORELINES_NGA & 21 \\
\hline INDONEISA_ACEH_PROVINCE_DAMAGE_LANDSATP131R058 & 22 \\
\hline INDONESIA_ACEH_PROVINCE_DAMAGE_LANDSAT9131R057 & 22 \\
\hline INDONESIA_ACEH_PROVINCE_DAMAGE_LANDSATP129R058 & 22 \\
\hline INDONESIA_ACEH_PROVINCE_DAMAGE_LANDSATP129R059 & 22 \\
\hline INDONESIA_ACEH_PROVINCE_DAMAGE_LANDSATP131R056 & 22 \\
\hline TSUNAMI_AFFECTED_HEALTH_FACILITIES_ACEH_PROVINCE & 22 \\
\hline TSUNAMI_AFFECTED_SHORELINE & 22 \\
\hline TSUNAMI_FLOODING_20043620420ACEH193M2P_DFO & 22 \\
\hline TSUNAMI_FLOODING_20043640405ACEH193M2P_DFO & 22 \\
\hline INDONESIA_POPDEN_2000 & 23 \\
\hline INDONESIA_POPDEN_2000_ADJUSTED & 23 \\
\hline LANDSCAN_POP_2002 & 23 \\
\hline LANDSCAN_POP_2003 & 23 \\
\hline
\end{tabular}

The Data Dictionary table utilizes the same coded value domain attributes as the feature classes in the Geodatabase. Figure 16 shows how this information is assigned to the table in ArcCatalog.

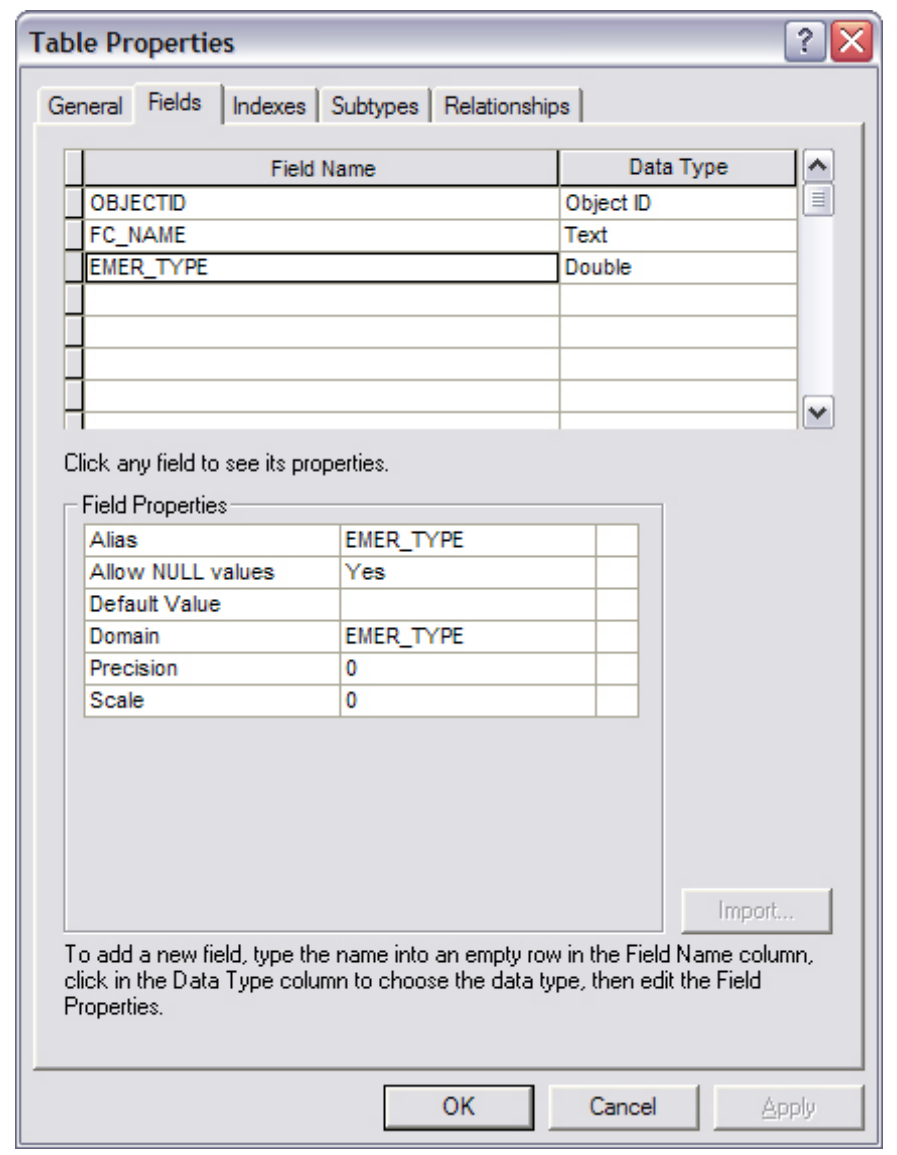

Figure 16: Data dictionary table using EMER_TYPE coded value domain 



\subsection{Geodatabase Design Implementation Stages}

The process of implementing the physical data model of a Geodatabase design occurs during a series of implementation stages (see Figure 14). The Project Geodatabase schema was developed by creating an empty geodatabase in ArcCatalog (Stage \#3, Option \#3) and importing data.

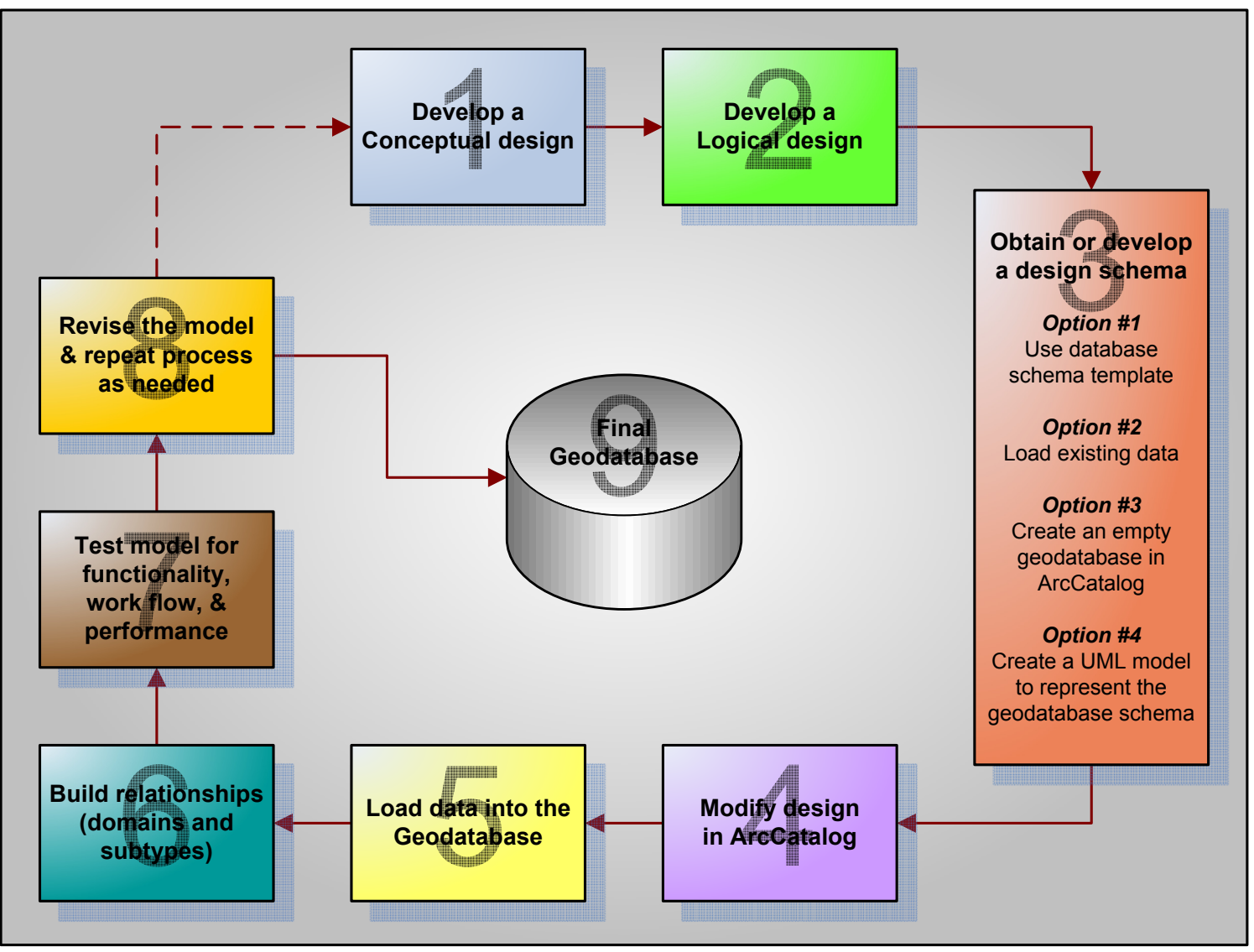

Figure 17: Geodatabase Implementation Process [Arctur and Zeiler, 2004, p. 377] 


\section{WebGIS Website Design}

ESRI's ArcIMS software has been used to develop a WebGIS website that serves as the internet-based portal to the Geodatabase. This website improves the accessibility of geographic information and the associated institutional knowledge to an international public audience of government agencies, emergency responders, humanitarian community IOs, and non-government organizations. The WebGIS website will provide remote access to the Geodatabase and support data discovery requirements when the physical geodatabase cannot be delivered to the field. Non-GIS users must be able to easily identify tools, data layers, and analysis processes that the website is capable of delivering.

\subsection{ArcIMS}

"ArcIMS is a server-based product that provides a scalable framework for distributing GIS services and data over the Web. [The software] enables websites to serve GIS data, interactive maps, metadata catalogs, and focused GIS applications" [ESRI, 2005a].

\subsubsection{Architecture}



Figure 18: ArcIMS Architecture [ESRI, 2005a]

\subsubsection{ArcMap Image Service}

The ArcIMS Administrator software was used to generate an ArcMap Image Service. An ArcIMS service allows the content of an ArcMap map document (.mxd) to be published directly on the internet. This service provides a significant advantage when working with feature classes and feature datasets from the Geodatabase. The information about the data layer content and symbology is transferred directly to the ArcIMS Spatial Server when the image is processed without the developer having to manipulate the data in any way. 


\subsubsection{HTML Viewer}

The WebGIS website client was designed using ArcIMS Designer and the HTML Viewer template. The HTML Viewer is the "best solution" [Kurnia and Hopkins, 2004, p. 5-4] for a wider distribution of end users who require lightweight applications that demand less processing. The HTML Viewer does not incorporate any Java applets and therefore does not require the user to download the Java 2 Plug-in on their local workstation. It accesses the image generated by the ArcIMS Spatial Server (ArcMap Image Service) rather than live-linked, streamed features. This decreases the applications bandwidth requirements while increasing its speed. Additionally, the viewer is highly customizable using both HTML and JavaScript programming. The HTML Viewer is supported for both Microsoft Internet Explorer and Netscape Navigator internet browsers.

\subsubsection{Data Delivery Extension}

The HTML Viewer is also recommended to support the ArcIMS Data Delivery Extension (DDE) pre-integration requirement. The ArcIMS DDE "provides the critical translation and delivery component of a solution that distributes data from any of the ArcIMS source data formats, while it simultaneously satisfies the needs of a [humanitarian] community needing data to be delivered in different formats and in different projections" [Safe Software Inc., 2004, p. 3]. Due to additional costs, this functionality will not be included in this project but can be added in future requirements and design models to increase the Geodatabase interoperability.

\subsubsection{Thematic Attribute Query}

The WebGIS website has been designed with a customized pull-down menu that lets a user identify a collection of pre-determined feature classes that correspond to the selected type of emergency. The pull-down menu selection will activate the corresponding feature classes in the Data Dictionary (see Section 2.3.6) and display them in the map frame of the WebGIS website. The user can then activate additional data layers that meet the specific needs of the analysis and map product being generated. The thematic attribute query functionality provides a proof-of-concept application of storing institutional knowledge about an issue that can be shared with non-GIS users of the humanitarian community not familiar with geographic information or organizational data standards. This utility will improve data discovery, analysis, and production timelines for users of the WebGIS website.

Figures 19-22 illustrate the design and application of a thematic attribute query tool within the WebGIS website user interface. The pull-down menu titled "Select an Emergency Type to View Data" provides the user access to all the feature classes and feature datasets that correspond to the selected EMER_TYPE coded value domain. This selection provides the user with a thematic attribute query capability that is not available on most metadata servers, ArcIMS websites, or FTP sites. At this point, the analysis and/or product can be continually customized to meet the mission requirements. 


\subsubsection{WebGIS Website Viewer Design}



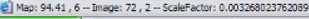

Y̧. Localintanes

\section{Figure 19: WebGIS website}

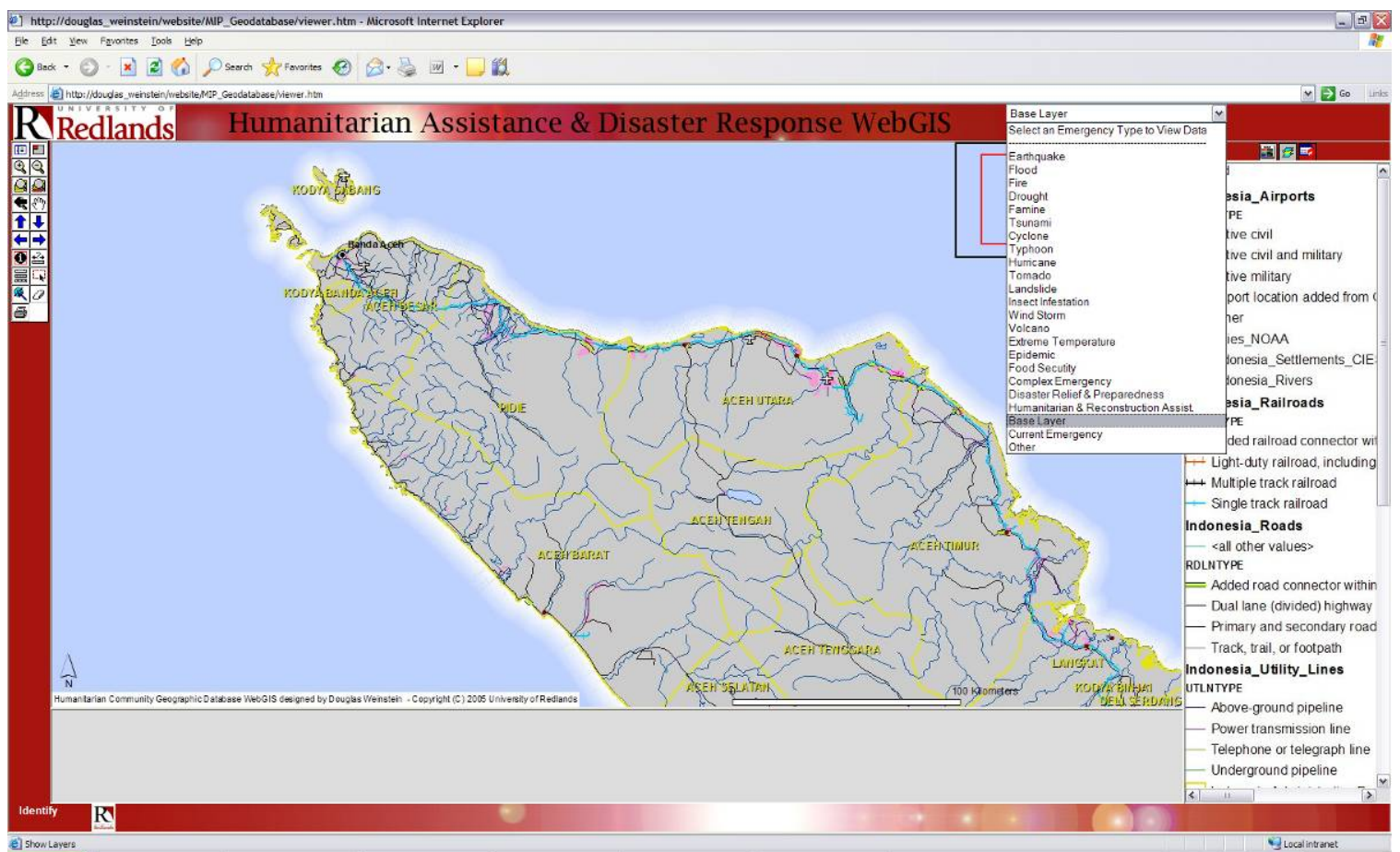

Figure 20: WebGIS website with Base Layer data selection 


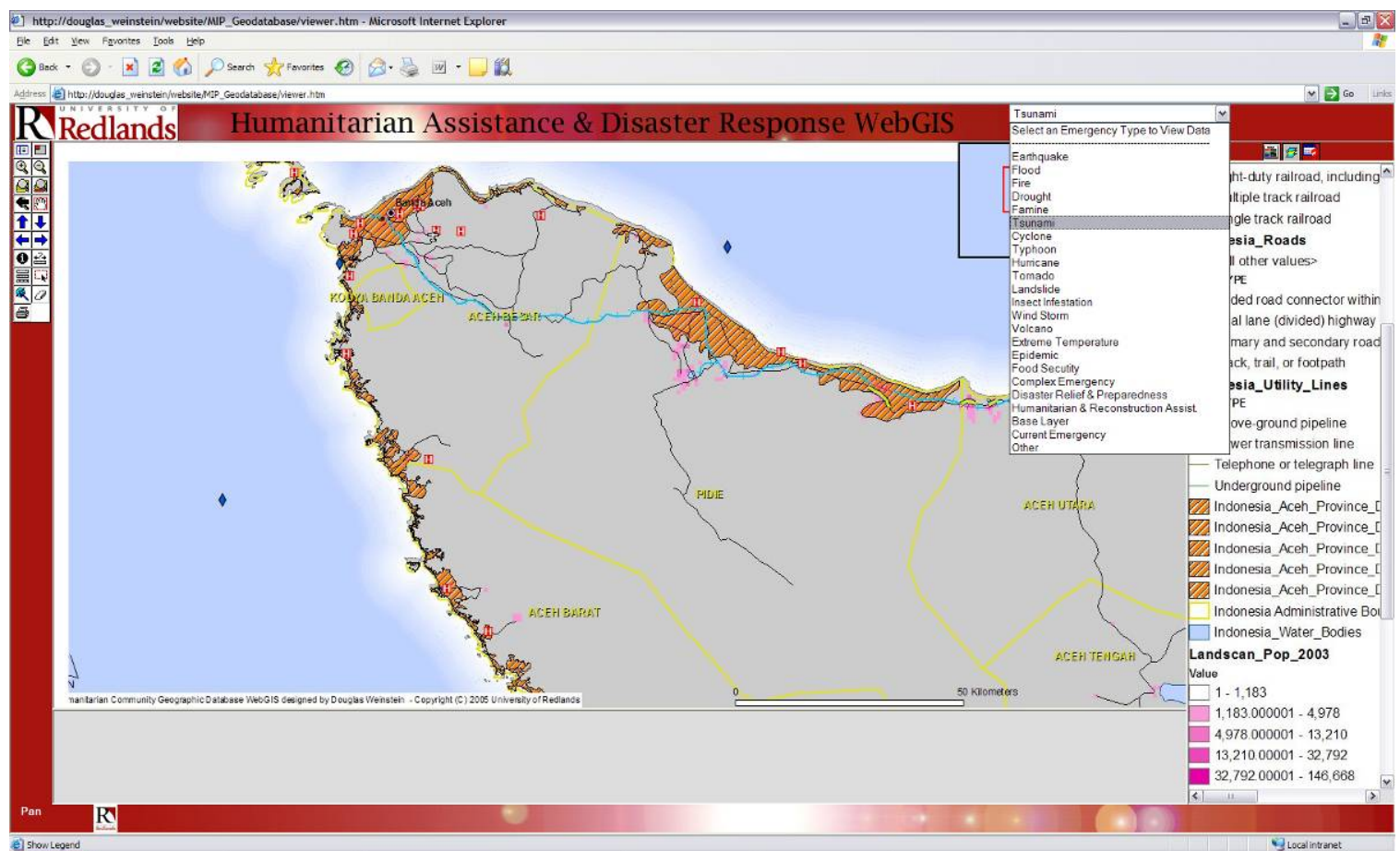

Figure 21: WebGIS website with Tsunami data selection

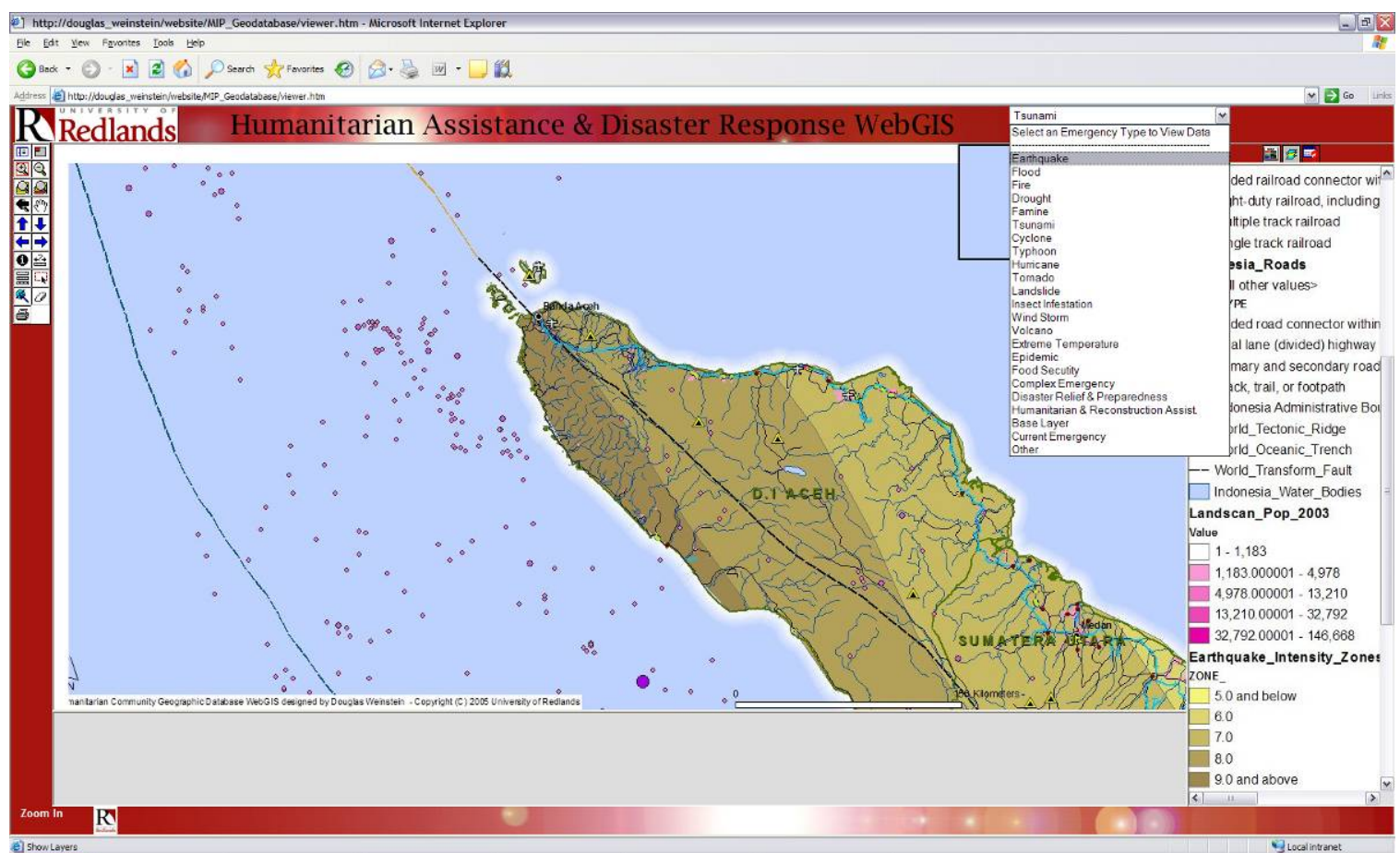

Figure 22: WebGIS website with Earthquake data selection 


\section{Project Implementation}

\subsection{Quality Assurance/Quality Control (QA/QC) Plan}

\subsubsection{Purpose}

A QA/QC Plan is a document describing in comprehensive detail the necessary Quality Assurance (QA), Quality Control (QC), and other technical activities that must be implemented to ensure that the results of the work performed will satisfy the stated performance criteria. The QA/QC Plan is developed by the Quality Assurance Team to ensure that all the developmental steps of the project are completed, reviewed, and reported in a systematic method to the client. The project QA/QC Plan will focus on the Geographic Database and WebGIS website deliverables and their adherence to the operational and quality needs of the humanitarian community.

\subsubsection{Objectives}

The objectives of the QA/QC Plan will be to document and communicate the QA and QC activities planned by the Quality Assurance Team. The QA/QC Plan will satisfy the task and deliverable requirements as determined by the Project Plan by assuring quality standards in the planning, implementation, assessment, and review of the project.

The data quality objectives of the QA/QC Plan are the most significant type due to their impact upon planning and decision-making activities within the humanitarian community. The following selected objectives focus on data quality:

- The intended use of the collected project data is to populate a geographic database that could be used by the humanitarian community in support of a humanitarian assistance or disaster response and recovery activities.

- The type of data needed for the geographic database will vary with the emergency response activity, but data collection will focus upon building an accurate and diverse framework of vector and raster thematic layers.

- Data will be collected from sources that are accessible to the international humanitarian community without any distribution limitations. These sources will primarily be government agencies, academia, and non-government organizations.

- When possible, the scale of the data should not exceed 1:250,000 to avoid vector data discrepancies and inaccuracy for large-scale analysis. Relying only upon small-scale data could potentially limit planning and decision-making. 


\subsubsection{Reference Documents}

The QA/QC Plan guidelines will be based upon the following project reference documents: the User Needs Analysis, the Project Plan, the Geodatabase conceptual, logical, and physical designs, and other project documentation.

\subsubsection{Acceptance Criteria Specifications}

Deliverable products may be considered acceptable by the humanitarian community if the format is interoperable, accessible, efficient, inexpensive, and accurate as compared with the current accepted standards. The Geodatabase and WebGIS website will deliver data that will not exceed a scale of 1:250,000 or the best available, is not restricted by sharing limitations, and is accessible with inexpensive and/or open-source technologies.

\subsubsection{Categories of Acceptance}

The project deliverables will not be categorized into levels of acceptance due to the restricted project timeframe and generally informal relationship with organizations within the humanitarian community. Any recommended or requested changes outside of the defined scope of the project will not be considered after completion and final submission of the project unless additional provisions are made (see Section 1.3.2).

\subsubsection{Visual Quality Control Checks}

Visual quality control of the project data will occur during the Project Review, Verification, and Validation phase of the QA/QC process by the Project Manager (see Appendix D). Using GIS analysis tools, the integrity and accuracy of the data can be verified and compared to existing data within the Geodatabase.

\subsubsection{Sampling}

All imported data will be verified to the greatest extent possible through a review of metadata documentation and source information and comparison to other existing base layers. Missing or inaccurate metadata will be replaced with the most current information when possible. Due to the restrictive timeframes of emergency response and recovery operations, $100 \%$ verification is not always possible.

\subsubsection{Quality Control Documentation}

The quality control documentation will be included in the final Project Documentation and in the corresponding Geodatabase metadata. All documentation will be provided in the Project Delivery phase (see Appendix D). 


\subsubsection{Environment Control}

The technical requirements for the completion of the project include ESRI's ArcGIS and ArcIMS software. ArcGIS 9.x will be used to process the geographic data and create the corresponding personal Geodatabase. ArcIMS will be used to create the WebGIS Website that will share the geographic data through a web browser connected to the internet. While these software licenses are recommended for optimal functionality and customization, the humanitarian community can use any GIS software products or applications that support vector and raster data formats (e.g. ESRI provides ArcReader free to the public) and any web browser connected to the internet to view the WebGIS website. No custom tools will be developed for the project.

\subsubsection{Quality Monitoring, Analysis, and Improvement}

The Project Work Flow/Process Flow (see Appendix A) and QA/QC Work Flow (see Appendix D) diagrams identify where quality monitoring, analysis, and improvement will occur throughout the project lifeline. 


\section{Project Conclusion}

\subsection{Conclusion}

The Project's recommended uses of a Geodatabase relational database management system and WebGIS website can potentially improve the efficiency and effectiveness of collaboration and data sharing in the humanitarian community. The models and designs discussed here will help to improve the organizational practices of humanitarian organizations and provide a potential solution to the "substantial problems in the way in which disaster-related information are collected, accessed, displayed, and disseminated" [SNDR, 2002] that is not simply a technological one. The development of the Geodatabase and WebGIS website has satisfied the goals of the Project to provide a solution that:

- Is compact and deployable,

- Improves functionality and efficiency,

- Reduces error and increases standardization,

- Records an institutional knowledge base, and

- Supports thematic attribute queries.

\subsection{Geodatabase Development Support}

The development of the Geodatabase and WebGIS website has been supported directly by professionals from the USG, humanitarian community, private sector, and academia. These individuals include:

- Rhonda Davis Stewart, OFDA

- Nate Smith, OFDA (former)

- Eric Sawyer, GIST

- Shawn Messick, VVAF/iMMAP

- Ray Carnes, ESRI

- Bryan Baker, ESRI

- Hugh Keegan, ESRI

- Gary MacDougall, ESRI

- Michael Goodchild, University of California Santa Barbara

- Mark Kumler, University of Redlands

- Marc Levine, USGS

\subsection{Deliverables}

At the conclusion of the Project and following the final presentation of the results, the Project Manger will deliver the following products upon request from a humanitarian community organization (see Appendices D and E). 


\subsubsection{Project Documentation}

The project documentation will consist of a softcopy and/or hardcopy Major Individual Project (MIP) final report entitled A Geographic Database Design for Humanitarian Assistance and Disaster Response. Additionally, a CD-ROM containing any associated documentation and data will be produced.

\subsubsection{Geodatabase and WebGIS Website}

The physical Geodatabase will be loaded to the final report CD-ROM and can be transferred from the provided media to a local source. The Geodatabase is compatible with ESRI ArcGIS software version 9.1 and above. The vector and raster geographic data is compatible with most geographic information system software platforms and will remain complete during the transfer process. All feature datasets, feature classes, object classes, relationship classes, coded value domains, and subtypes can be customized by the receiving organization using ESRI's ArcGIS software. The WebGIS website design will be provided on the final report CD-ROM as an HTML website with the associated files.

\subsection{Humanitarian Community Support}

\subsubsection{Training}

An informal training program will be developed with the coordinating humanitarian assistance organization. This one-day training activity will focus on educating the potential GIS manager, core GIS staff, and GIS end users about the methodologies and requirements that support the Project's recommendations. Due to limited project resources, training will occur face-to-face in an on-site location and will not include "web-based training, distance learning, or development of self-study workbooks" [Tomlinson, 2003, p. 216].

\subsubsection{Technical Assistance}

Specific technical support may be provided by the software vendor, data provider, data originator, or coordinating organization. Technical assistance that is outside of the defined scope of the project will not be provided by the Project Manager after completion and final submission of the project unless additional provisions have been made (see Section 1.3.2). 


\subsection{Presentation of Results}

The final results and recommendations of the Project are planned to be presented to a professional audience at the following locations:

- 2005 ESRI International User Conference in San Diego, CA

- USAID U.S. Office of Foreign Disaster Assistance in Washington, DC

- National Geospatial-Intelligence Agency in Washington, DC

Copies of this final report will be made available by the Author upon request. 


\section{References}

AIMS Project (UNDP). "Information Management for Natural Disasters: Pilot Project for Kabul \& Kunduz Province". Kabul, 2004. (26 Sep 2004): UN Assistance Mission in Afghanistan (UNAMA). 03 Jun 2005.

$<$ http://www.aims.org.af/services/sectoral/d m/dmis for afg a $\mathrm{p} \_$p.pdf $>$.

Arctur, David and Michael Zeiler. Designing Geodatabases: Case Studies in GIS Data Modeling. Redlands: ESRI Press, 2004.

Cartwright, John C. and Ted Habermann. "Managing and Distributing Geospatial Data at NGDC". Redlands, 2000. ESRI International User Conference Proceedings. ESRI. 12 Jul 2005. <http://gis.esri.com/library/userconf/proc00/professional/papers/PAP964/p964.htm $>$.

Canserina, Kurnia and Danielle Hopkins. "Introduction to ArcIMS." 5.2 ed. Redlands: ESRI Educational Services, 2004.

CRED. "CRED Crunch - Disaster Data: A Balanced Perspective". Brussels, 2005. Centre for Research on the Epidemiology of Disasters. May 2005.

Codd, Edgar F. "A Relational Model of Data for Large Shared Data Banks." Communications of the ACM 13.6 (1970): 377-87.

Columbia University. "Center for International Earth Science Information Network (CIESIN)". New York, 2005. Columbia University. 16 Jun 2005.

$<$ http://www.ciesin.columbia.edu/ $>$.

ESRI. Geodatabase Design Concepts (Final). 2.2 ed. Redlands: ESRI Educational Services, 2004.

ESRI. "ArcIMS". Redlands, 2005a. (06 Jan 2005): ESRI. 10 Jun 2005.

<http:/www.esri.com/software/arcgis/arcims/index.html $>$.

ESRI. "ArcSDE \& Geodatabase System Tables." Ed. ArcSDE Developer Help 9.1. Redlands: ESRI, 2005b.

ESRI. "Geodatabase". Redlands, 2005c. (06 Jan 2005): ESRI. 17 Jun 2005.

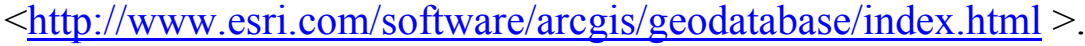

ESRI. "GIS Dictionary". Redlands, 2005d. (01 Jun 2005): ESRI. 26 Jun 2005.

$<\underline{\text { http://support.esri.com/index.cfm?fa }=\text { knowledgebase.gisDictionary.gateway }}>$. 
Eraslan, C., Z. Alkis, O. Emem, C. Helvaci, F. Batuk, U. Gumusay, N. Demir, T. Turk, B. Bayram, and A. Alkis. "System Design of Disaster Management Information System in Turkey as a Part of E-Government". Istanbul, 2004. YTU, Department of Geodesy and Photogrammetry. 01 Jun 2005.

$<$ http://www.isprs.org/istanbul2004/comm2/papers/139.pdf $>$.

Federal Emergency Management Agency. "FEMA Fifth Annual Performance Plan Fiscal Year 2002". 2002. FEMA. 12 Jun 2005.

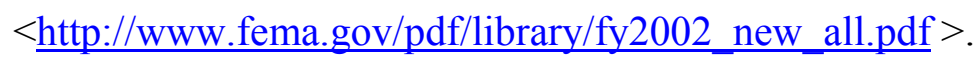

Federal Emergency Management Agency. "Hazardmaps.gov: The Multi-Hazard Mapping Initiative - MMI". Washington, D.C., 2005. FEMA. 18 Jul 2005.

<http://www.hazardmaps.gov/atlas.php $>$.

Geographic Information Support Team. "Geographic Information Support Team Data Repository". 2005. University of Georgia. 10 Jun 2005. < https://gist.Geographic Information Support Team.uga.edu/index.asp $>$.

Johnson, Russ. "GIS Technology for Disasters and Emergency Management". Redlands, 2000. ESRI White Paper. ESRI. 01 Jun 2005.

$<$ http://www.esri.com/library/whitepapers/pdfs/disastermgmt.pdf $>$.

Mansourian, A., A. Rajabifard, M. J. Valadan Zoej, and I. Williamson. "Facilitating Disaster Management Using SDI". Tehran, 2004. K. N. Toosi University of Technology. 18 Jul 2005.

$<\underline{\text { http://www.sli.unimelb.edu.au/research/SDI_research/publications/files/Geo Engineeri }}$ ng HK2004.pdf $>$.

Meissner, Andreas, Thomas Luckenbach, Thomas Risse, Thomas Kirste, and Holger Kirchner. "Design Challenges for an Integrated Disaster Management Communication and Information System". Darmstadt, 2002. Fraunhofer Integrated Publication and Information Systems Institute. 01 Jun 2005.

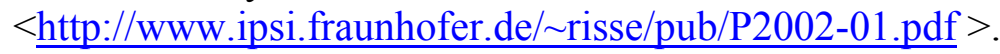

Organization of American States. "Disasters, Planning and Development: Managing Natural Hazards to Reduce Loss". Washington, D.C., 1990. Ed. Department of Regional Development and Environment Executive Secretariat for Economic and Social Affairs Organization of American States. OAS Natural Hazards Project of the Department of Regional Development and Environment. 14 Jul 2005. < http://www.oas.org/ >.

Republic of Indonesia. "Master Plan for the Rehabilitation and Reconstruction of the Regions and Communities of the Province of Nanggroe Aceh Darussalem and the Islands of Nias, Province of North Sumatra." Jakarta: Republic of Indonesia, 2005. 126. 
Safe Software Inc. "ArcIMS Data Delivery Extension (DDE) Reference Manual". Redlands, 2004. ESRI. 19 Jul 2005.

$<$ http://downloads.esri.com/support/documentation/other_DDE_RefGuide_Updated0904 $. \underline{\mathrm{pdf}}>$.

Sida, Lewis and Chris Szpak. An Evaluation of Humanitarian Information Centers: Case Studies of HICs for Iraq, Afghanistan, and Liberia: USAID/OFDA and DFID, 2004.

SNDR "A National Hazards Information Strategy: Reducing Disaster Losses through Better Information". Washington, D.C., April 2002. National Science and Technology Council, Committee on the Environment and Natural Resources, Subcommittee on Natural Disaster Reduction (SNDR).

Taggart, Marnel and Mike Ridland. "Use Subtypes and Domains for Automatic Attribute Validation." ArcUser Apr - Jun 2000: 38-39.

Tomlinson, Roger. Thinking About GIS: Geographic Information System Planning for Managers. 1 ed. Redlands: ESRI Press, 2003.

United Nations Office for the Coordination of Humanitarian Affairs. "Humanitarian Information Centres". 2005. Information Technology Section. 10 Jun 2005.

$<$ http://www.humanitarianinfo.org $>$.

U.S. Agency for International Development. "2003 OFDA Annual Report". Washington, D.C., 2003. USAID/OFDA2005.

$<$ http://www.usaid.gov/our_work/humanitarian_assistance/disaster_assistance/publicatio ns/annual reports/index.html $>$.

U.S. Agency for International Development, Office of U.S. Foreign Disaster Assistance. "USAID/OFDA 40th Anniversary 1964-2004." Washington, DC: USAID, 2004.

U.S. Geological Survey Earthquake Hazards Program. "Earthquake Facts and Statistics: Frequency of Occurrence of Earthquakes". Washington, D.C., 2005. (12 Jul 2005): USGS. 23 Jul 2005. < http://neic.usgs.gov/neis/eqlists/eqstats.html >.

Webopedia. "Data Dictionary". 2005. Webopedia. 12 Jul 2005. $<$ http://www.webopedia.com/TERM/D/data_dictionary.html $>$.

Zeiler, Michael. Modeling Our World: The ESRI Guide to Geodatabase Design. Redlands: ESRI Press, 1999. 


\section{Appendix A: USAID/OFDA Data Inventory Examples}

I. Sahelian Africa Locust Emergency 2004

a. Raster Data

i. Disaster Response Map products

1. Current Locust Invasion, Potential Summer Migration Patterns, and Areas of Outbreak, USAID/OFDA

2. Mauritania Administrative Map

3. Senegal Administrative Map

4. Incident Response Planning Map template, USAID/OFDA/DART

5. Locust Control Campaign Accomplishment Map template (sprayed areas), USAID/OFDA/DART

6. Locust Control Campaign Airport Zones Map template, USAID/OFDA/DART

7. Flight Planning Graphics, USAID/OFDA/DART

a. Kaedi

b. Podor

c. St. Louis

d. Theater

8. Locust Mortality in Areas Sprayed Map, Mederdra Region, USAID/OFDA/DART

9. Daily Flight Summary Maps (12Oct04 - 10Nov04), USAID/OFDA/DART

b. Vector Data

10. Aerial Spray Targeting Map template, USAID/OFDA/DART

i. Locust Spray Zone Buffer polygons

ii. Africa Major Towns points

iii. Locust Spray Zone Target polygons

iv. Locust Spray Areas polygons, Mali

c. Tabular Data

i. GPS Archive

d. Documentation

i. Desert Locust Guidelines

ii. Guidelines for Pesticide Trials on Desert Locust Hoppers

iii. FAO Desert Locust Survey and Control Form

iv. FAO Spray Monitoring Form

v. SOP For Desert Locust Ground Survey

vi. Critical Supply Tracking Sheet

vii. DART Locust Update

viii. DART Situation Report

ix. USAID Situation Report: Sahelian Africa - Locust Emergency

x. Locust Spray Mission logs, Mali

xi. Daily Flight Schedule Reports

xii. Flight Reports

xiii. Photographs

II. Bam, Iran Earthquake 26Dec03

a. Raster Data

i. 1:50,000 Iran

ii. 1:25,000 US JOGA

iii. Geological Map of Iran, Geological Survey of Iran

iv. Commercial Imagery

1. Ikonos MSI

2. Quickbird MSI 
3. Landsat7

v. Disaster Response Map products

1. Operations Reference Map, USAID OFDA GIU

2. Old City of Bam, Iran: Pre and Post Quake Imagery, USAID/OFDA/GIU

3. Satellite Map of Bam City, (Kerman Province, Iran), German Remote Sensing Data Center of the German Aerospace Center

4. Satellite Map of Bam City, (Kerman Province, Iran) - Northern Part, German Remote Sensing Data Center of the German Aerospace Center

5. Satellite Map of Bam City, (Kerman Province, Iran) - Southern Part, German Remote Sensing Data Center of the German Aerospace Center

6. Earthquake Damage as seen from Space: Bam, Iran, USAID/OFDA

7. Estimated Locations of Mosques, Hospitals, and Schools: Bam, Iran, USAID/OFDA

8. Estimated Population Directly Affected by Bam Earthquake, USAID/OFDA

b. Vector Data

i. Damaged Area polygons

ii. Hospitals, Schools, Mosques points

iii. Road polylines

c. Documentation

i. Damage Mapping of Bam City Area (Iran) after the December 26, 2003

Earthquake, Geosciences Consultants/Space Imaging

ii. Photographs

III. Democratic Republic of Congo (DRoC) Nyiragongo volcano 17Jan02

a. Raster Data

i. Goma Lava Flow History Map

ii. DRoC Administrative Map

iii. Commercial Imagery

1. Landsat7

2. Spot5 PAN

iv. Disaster Response Map Products

1. Nyiragongo Volcano Damage Assessment: Northern Goma, DRoC

2. Nyiragongo Volcano Damage Assessment: Southern Goma, DRoC

3. Nyiragongo Volcano Lava Flow Assessment: DRoC

4. Nyiragongo Volcano Reference Map, NGA

5. Goma, DRoC, UNHCR/GIMU

b. Vector Data

i. Road polylines

ii. Administrative Boundary polylines

iii. Lava Flow polygon

c. Documentation

i. DRoC Volcano Fact Sheet, USAID/OFDA

ii. Photographs 


\section{Appendix B: Project Data Requirements}

\begin{tabular}{|c|c|c|c|c|c|}
\hline \multirow{2}{*}{ Dataset } & \multicolumn{3}{|c|}{ Relative Scale Ranges } & \multirow{2}{*}{ Applications/Use } & \multirow{2}{*}{ Expected Provider } \\
\hline & Small & Medium & Large & & \\
\hline Administrative boundaries & $\mathrm{X}$ & & & Humanitarian relief operations & NGA/USGS \\
\hline Airports/runways & & $\mathrm{X}$ & & Humanitarian relief operations & NGA/USGS \\
\hline Aerial photography & & & $\mathrm{X}$ & $\begin{array}{l}\text { Disaster impacts assessment/Hazard and } \\
\text { vulnerability mapping (volcano, } \\
\text { landslide, desertification) }\end{array}$ & Local source \\
\hline Disaster information (current) & & & $\mathrm{X}$ & Hazard and vulnerability mapping & $\begin{array}{l}\text { USGS/DFO/OFDA/ } \\
\text { CRED/UN }\end{array}$ \\
\hline Disaster information (historical) & & & $\mathrm{X}$ & $\begin{array}{l}\text { Hazard and vulnerability mapping } \\
\text { (flood) }\end{array}$ & $\begin{array}{l}\text { USGS/DFO/OFDA/ } \\
\text { CRED/UN }\end{array}$ \\
\hline Fire departments & & $\mathrm{X}$ & & Humanitarian response resources/Shelter & Local source \\
\hline Geology & $\mathrm{X}$ & & & $\begin{array}{l}\text { Earthquake/tsunami modeling/erosion } \\
\text { modeling }\end{array}$ & USGS \\
\hline Geophysical & $\mathrm{X}$ & & & Earthquake/tsunami modeling & $\begin{array}{l}\text { UT Institute for } \\
\text { Geophysics/UN }\end{array}$ \\
\hline $\begin{array}{l}\text { High-resolution commercial satellite } \\
\text { imagery (Quickbird, Ikonos, } \\
\text { ORBIMAGE, SPOT) }\end{array}$ & & & $\mathrm{X}$ & $\begin{array}{l}\text { Disaster impacts assessment/Hazard and } \\
\text { vulnerability mapping }\end{array}$ & $\begin{array}{l}\text { USGS/PDC/UNOSAT/ } \\
\text { USAID }\end{array}$ \\
\hline Hospitals/health centers & & $\mathrm{X}$ & & Humanitarian relief resources/Shelter & $\mathrm{UN}$ \\
\hline Hydrography (rivers, streams, lakes) & $\mathrm{X}$ & & & Flood plain mapping & NGA/USGS \\
\hline $\begin{array}{l}\text { Hypsography/Topographic (digital } \\
\text { elevation model, point elevation) }\end{array}$ & $\mathrm{X}$ & & & $\begin{array}{l}\text { Flood modeling/Visualization/Hazard } \\
\text { and vulnerability mapping (hurricane) }\end{array}$ & NGA/USGS \\
\hline Land cover/land use, AVHRR & $\mathrm{X}$ & & & $\begin{array}{l}\text { Land cover and land use mapping, } \\
\text { vegetation monitoring }\end{array}$ & $\begin{array}{l}\mathrm{FAO} / \mathrm{WFP} / \mathrm{USGS} / \\
\text { NOAA }\end{array}$ \\
\hline $\begin{array}{l}\text { Moderate-resolution civil satellite } \\
\text { imagery (Landsat, MODIS, ASTER) }\end{array}$ & & $\mathrm{X}$ & & $\begin{array}{l}\text { Hazard and vulnerability mapping } \\
\text { (desertification) }\end{array}$ & USGS/PDC/UNOSAT \\
\hline NaturalVue global satellite imagery & & $\mathrm{X}$ & & $\begin{array}{l}\text { Disaster impacts assessment/Hazard and } \\
\text { vulnerability mapping }\end{array}$ & EarthSat \\
\hline Police departments & & $\mathrm{X}$ & & Humanitarian response resources/Shelter & Local source \\
\hline Population centers & $\mathrm{X}$ & & & Hazard and vulnerability mapping & CIESIN \\
\hline Population density & $\mathrm{X}$ & & & Hazard and vulnerability mapping & CIESIN \\
\hline Population distribution & $\mathrm{X}$ & & & Hazard and vulnerability mapping & ORNL \\
\hline Railroads & & $\mathrm{X}$ & & $\begin{array}{l}\text { Humanitarian relief } \\
\text { operations/Evacuation/Lines-of- } \\
\text { communication }\end{array}$ & NGA \\
\hline Religious centers & & $\mathrm{X}$ & & Humanitarian relief resources/Shelter & $\mathrm{UN}$ \\
\hline Roads & & $\mathrm{X}$ & & $\begin{array}{l}\text { Humanitarian relief } \\
\text { operations/Evacuation/Lines-of- } \\
\text { communication }\end{array}$ & NGA \\
\hline Schools & & $\mathrm{X}$ & & Humanitarian relief resources/Shelter & $\mathrm{UN}$ \\
\hline Soils & $\mathrm{X}$ & & & $\begin{array}{l}\text { Agricultural production/erosion } \\
\text { modeling }\end{array}$ & USGS \\
\hline $\begin{array}{l}\text { Synthetic Aperture Radar } \\
\text { (SAR)/Airborne radar }\end{array}$ & & & $\mathrm{X}$ & $\begin{array}{l}\text { Disaster impacts assessment/Hazard and } \\
\text { vulnerability mapping (flood, earthquake, } \\
\text { land cover) }\end{array}$ & RADARSAT \\
\hline Thermal infrared (IR) scanner & & $\mathrm{X}$ & & $\begin{array}{l}\text { Hazard and vulnerability mapping } \\
\text { (volcano) }\end{array}$ & USGS \\
\hline Water sources (potable/non-potable) & & $\mathrm{X}$ & & Humanitarian relief resources & Local source \\
\hline Watershed delineation & $\mathrm{X}$ & & & Erosion and flood modeling & USGS \\
\hline Weather (historical) & $\mathrm{X}$ & & & Cloud cover and rainfall estimates & NOAA \\
\hline
\end{tabular}




\section{Appendix C: Project Work Flow/Process Flow}

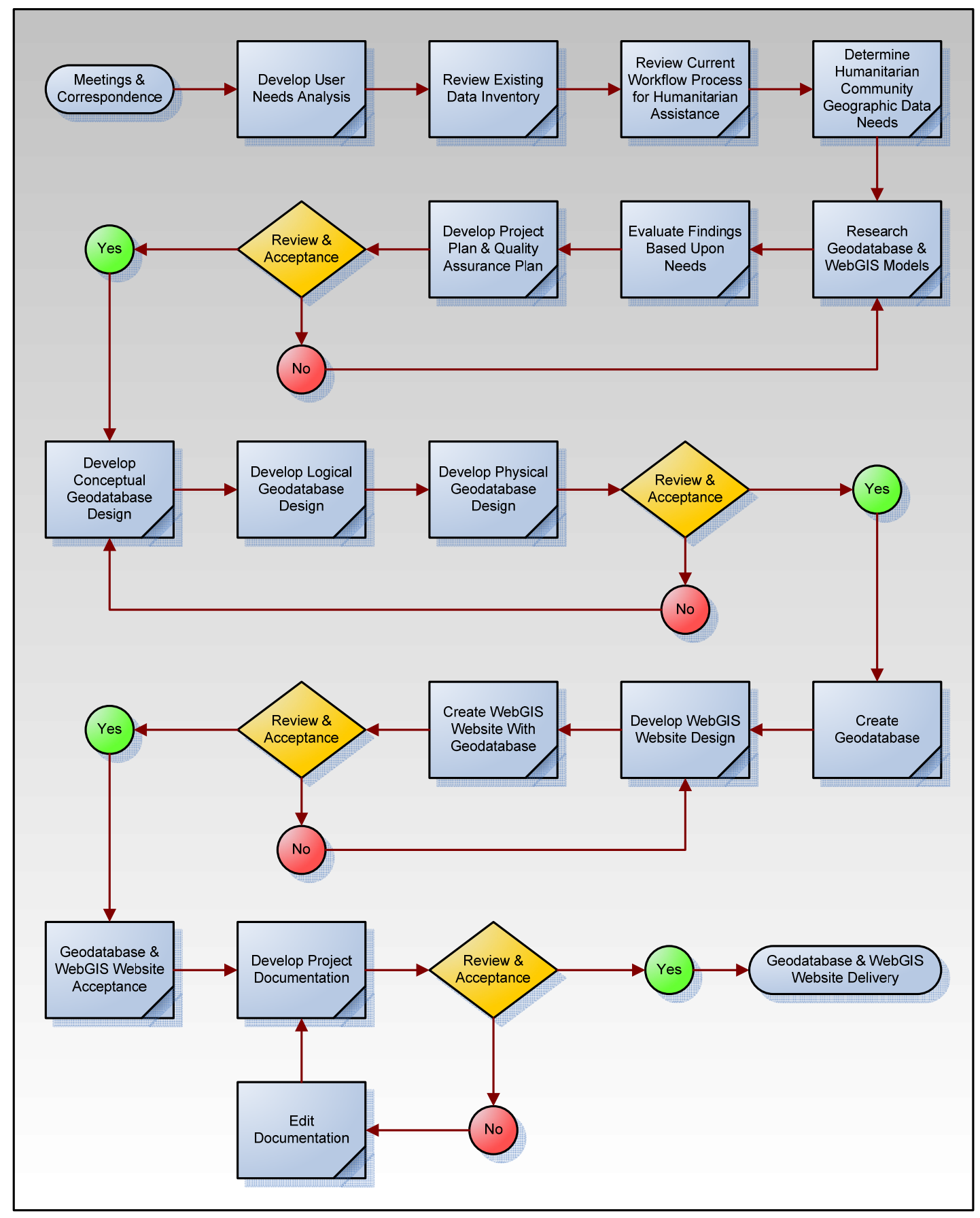




\section{Appendix D: Project Schedule}






\section{Appendix E: Project Tasks}

\begin{tabular}{|c|c|c|c|}
\hline Project Task Name & Duration & Start Date & End Date \\
\hline $\begin{array}{l}\text { A Geographic Database Design for Humanitarian } \\
\text { Assistance and Disaster Response }\end{array}$ & $736 \mathrm{hrs}$ & Fri 9/10/04 & Mon 1/10/06 \\
\hline Project Definition & $136 \mathrm{hrs}$ & Fri 9/10/04 & Mon 9/19/05 \\
\hline Administration & $48 \mathrm{hrs}$ & Fri 9/10/04 & Mon 9/19/05 \\
\hline Meetings and Correspondence & $40 \mathrm{hrs}$ & Fri 9/10/04 & Mon 9/19/05 \\
\hline $\begin{array}{l}\text { The National Academies Disasters Roundtable } \\
\text { Conference: Indian Ocean Tsunami Disaster }\end{array}$ & $8 \mathrm{hrs}$ & Tue $6 / 21 / 05$ & Tue $6 / 21 / 05$ \\
\hline User Needs Analysis & $40 \mathrm{hrs}$ & Thu 10/21/04 & Mon 4/4/05 \\
\hline Project Proposal & $24 \mathrm{hrs}$ & Mon 3/7/05 & Fri 4/29/05 \\
\hline Project Plan & $24 \mathrm{hrs}$ & Mon 4/18/05 & Mon 5/9/05 \\
\hline Project Development & $232 \mathrm{hrs}$ & Tue $11 / 23 / 04$ & Fri $7 / 1 / 05$ \\
\hline Geographic Data Inventory & $104 \mathrm{hrs}$ & Tue $11 / 23 / 04$ & Fri $7 / 1 / 05$ \\
\hline Geographic Data Collection & $80 \mathrm{hrs}$ & Tue $11 / 23 / 04$ & Fri $4 / 29 / 05$ \\
\hline Geographic Data Review & $24 \mathrm{hrs}$ & Mon 5/2/05 & Fri $7 / 1 / 05$ \\
\hline Geodatabase Design & $88 \mathrm{hrs}$ & Mon 12/6/04 & Fri 6/24/05 \\
\hline Geodatabase Architecture & $16 \mathrm{hrs}$ & Mon $12 / 6 / 04$ & Wed $12 / 22 / 04$ \\
\hline Conceptual Model Design & $16 \mathrm{hrs}$ & Mon $1 / 10 / 05$ & Fri $1 / 21 / 05$ \\
\hline Logical Model Design & $16 \mathrm{hrs}$ & Mon 3/7/05 & Fri 3/25/05 \\
\hline Physical Model Design & $40 \mathrm{hrs}$ & Mon $4 / 4 / 05$ & Fri 6/24/05 \\
\hline WebGIS Website Design & $40 \mathrm{hrs}$ & Tue $3 / 1 / 05$ & Fri 5/27/05 \\
\hline Project Implementation & $144 \mathrm{hrs}$ & Mon 4/18/05 & Tue $8 / 2 / 05$ \\
\hline Quality Assurance/Quality Control (QA/QC) Plan & $24 \mathrm{hrs}$ & Mon 4/18/05 & Mon 5/9/05 \\
\hline Geodatabase Development & $40 \mathrm{hrs}$ & Wed 6/29/05 & Tue $8 / 2 / 05$ \\
\hline WebGIS Website Development & $80 \mathrm{hrs}$ & Mon 5/30/05 & Tue $8 / 2 / 05$ \\
\hline Project Conclusion and Transition & $224 \mathrm{hrs}$ & Mon 5/9/05 & Mon 1/10/06 \\
\hline Deliverables & $96 \mathrm{hrs}$ & Mon 5/9/05 & Mon 9/12/05 \\
\hline \multirow{4}{*}{\begin{tabular}{c|c} 
& Projec \\
\cline { 2 - 2 } & Geod \\
\cline { 2 - 2 } & WebC \\
\multicolumn{2}{|c|}{ Support }
\end{tabular}} & $80 \mathrm{hrs}$ & Mon 5/9/05 & Wed 7/27/05 \\
\hline & $8 \mathrm{hrs}$ & Tue $8 / 2 / 05$ & Mon 9/12/05 \\
\hline & $8 \mathrm{hrs}$ & Tue $8 / 2 / 05$ & Mon $9 / 12 / 05$ \\
\hline & $16 \mathrm{hrs}$ & Mon 9/12/05 & Fri 9/16/05 \\
\hline \begin{tabular}{|l|l|} 
& Training \\
\end{tabular} & $8 \mathrm{hrs}$ & Mon 9/12/05 & Fri 9/16/05 \\
\hline Technical Assistance & $8 \mathrm{hrs}$ & Mon $9 / 12 / 05$ & Fri 9/16/05 \\
\hline Preparation and Presentation of Results & $112 \mathrm{hrs}$ & Thu $7 / 21 / 05$ & Mon 9/19/05 \\
\hline Project Poster & $40 \mathrm{hrs}$ & Thu $7 / 14 / 05$ & Fri $7 / 21 / 05$ \\
\hline Project Briefing/Defense & $16 \mathrm{hrs}$ & Thu $7 / 31 / 05$ & Mon 8/02/05 \\
\hline 2005 ESRI International User Conference & $40 \mathrm{hrs}$ & Mon 7/25/05 & Fri $7 / 28 / 05$ \\
\hline $\begin{array}{l}\text { USAID U.S. Office of Foreign Disaster } \\
\text { Assistance }\end{array}$ & $8 \mathrm{hrs}$ & Mon 1/9/06 & Mon 1/9/06 \\
\hline National Geospatial-Intelligence Agency & $8 \mathrm{hrs}$ & Mon 1/10/06 & Mon 1/10/06 \\
\hline
\end{tabular}




\section{Appendix F: Quality Assurance/Quality Control Work Flow}






\section{Appendix G: Data Sources}






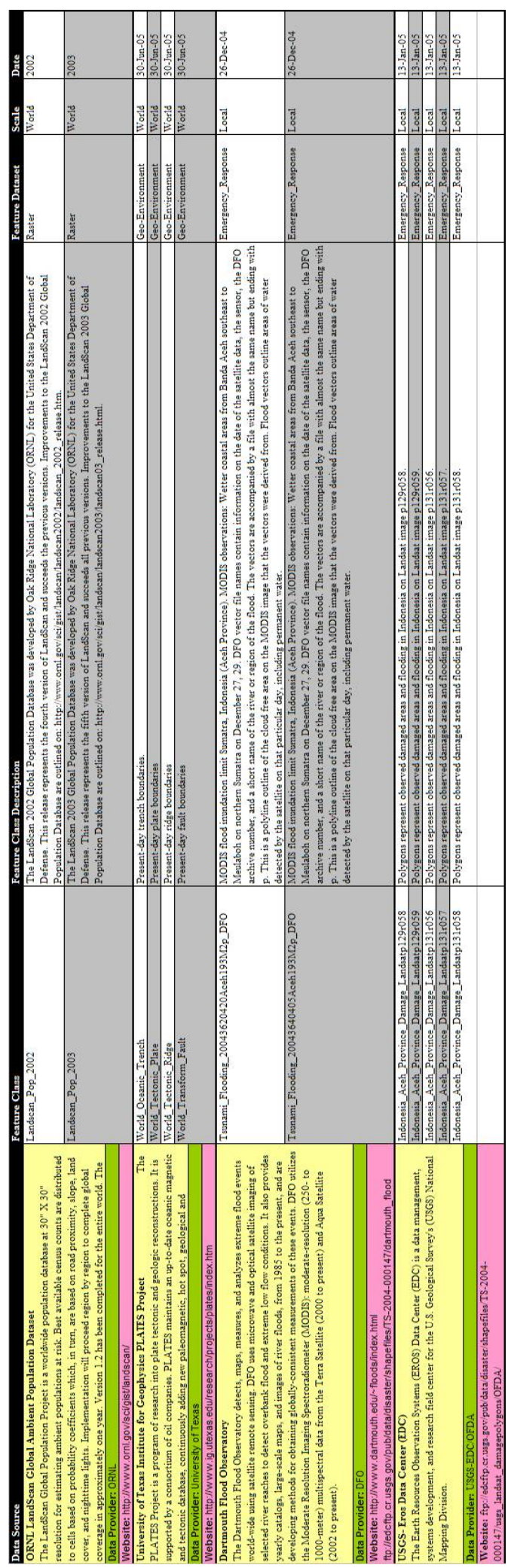




\section{Appendix H: Analysis Map Products}

Figures 23 and 24 are examples of analysis products that could be produced utilizing various thematic data sets from the WebGIS website. These map products combine disaster-related information such as:

- Vector administrative boundaries and population centers

- Terrain visualization

- Raster population estimates

- $\quad$ Earthquake epicenter

- Estimated extent of flooded shorelines

- Geotechnical information

- Landsat moderate-resolution imagery base

- DigitalGlobe high-resolution imagery insets

These products can provide emergency responders and decision-makers with an important common operating picture to make coordinated decisions about a disaster response. The Geodatabase and the thematic attribute query of the WebGIS website improve the production of analysis map products such as these. 


\section{Humanitarian Assistance and Disaster Response}

December 26, 2004 Earthquake \& Tsunami Damage: Sumatra, Indonesia



Figure 23: Analysis Map Product \#1 


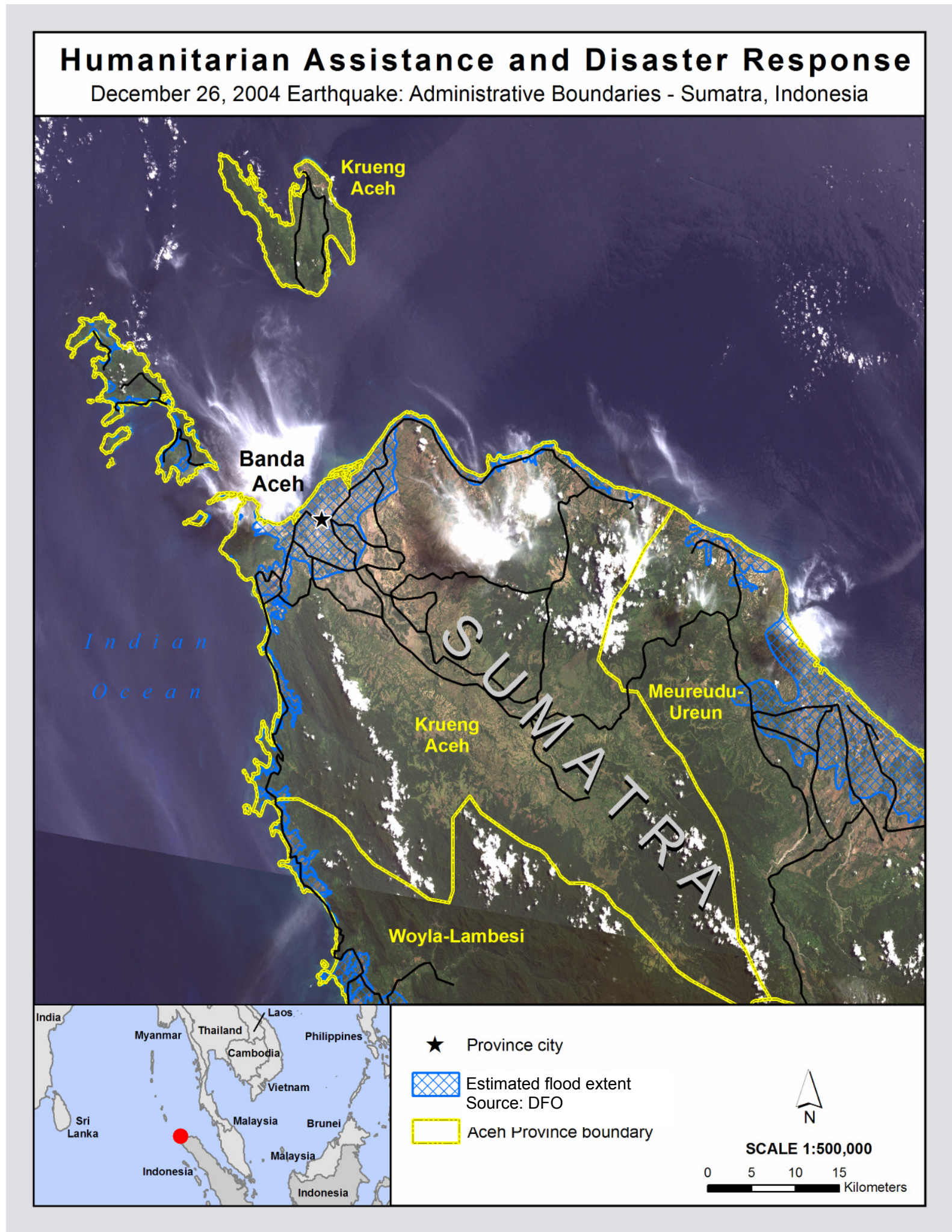

Figure 24: Analysis Map Product \#2 